NBER WORKING PAPER SERIES

\title{
STOCK MARKET CYCLES, FINANCIAL LIBERALIZATION AND VOLATILITY
}

Sebastian Edwards

Javier Gomez Biscarri

Fernando Perez de Gracia

Working Paper 9817

http://www.nber.org/papers/w9817

\author{
NATIONAL BUREAU OF ECONOMIC RESEARCH \\ 1050 Massachusetts Avenue \\ Cambridge, MA 02138 \\ July 2003
}

The views expressed herein are those of the authors and not necessarily those of the National Bureau of Economic Research

(C2003 by Sebastian Edwards, Javier Gomez Biscarri, and Fernando Perez de Gracia. All rights reserved. Short sections of text not to exceed two paragraphs, may be quoted without explicit permission provided that full credit including (C) notice, is given to the source. 
Stock Market Cycles, Financial Liberalization and Volatility

Sebastian Edwards, Javier Gomez Biscarri, and Fernando Perez de Gracia

NBER Working Paper No. 9817

July 2003

JEL No. F30, C22, G15

\begin{abstract}
In this paper we analyze the behavior of stock markets in six emerging countries. More specifically, we describe the bull and bear cycles of four Latin American and two Asian countries, comparing their characteristics during both phases and the degree of concordance of bullish periods. We divide our sample in two subperiods in order to account for differences induced by the financial liberalization processes that these countries went through in the early 1990's. We find that cycles in emerging countries tend to have shorter duration and larger amplitude and volatility than in developed countries. However, after financial liberalization Latin American stock markets have behaved more similarly to stock markets in developed countries whereas Asian countries have become more dissimilar. Concordance of cycles across markets has increased significantly over time, especially for Latin American countries after liberalization.
\end{abstract}

Sebastian Edwards

Javier Gomez Biscarri

Fernando Perez de Gracia

Anderson School of Management

UCLA

110 Westwood Plaza

P.O. Box 951481

Los Angeles, CA 90095-1581

and NBER

sedwards@anderson.ucla.edu 


\section{Introduction}

During the last decade the emerging markets have been characterized by a high degree of financial instability. This has been particularly the case in Latin America, where currency crises have become recurrent, and where equity markets have experienced dramatic swings. Partially motivated by this instability, a number of authors have recently investigated the behavior of Latin American financial markets. ${ }^{1}$ Fischer (2002), for example, has analyzed the implications of the Latin American currency crises for the future of the international monetary system. Eichengreen (2003), De Gregorio et al. (2000), and Edwards (1999) have investigated the role played by capital mobility in Latin America during the financial crises of the 1990s. Goldstein (2003) has looked more specifically at the forces behind the financial turmoil in Brazil during 2002.

Rigobon (2002) has focused on alternative volatility measures in both equity and bond markets in the period surrounding recent financial crises. Kaminsky and Reinhart (2002) have investigated how interest rates, equity returns and bond spreads behave in times of global financial stress. Their main interest was to analyze whether these variables exhibited co-movement across countries. Bekaert and Harvey (2000) analyzed equity returns in a group of emerging markets, including six Latin American countries, before and after the financial reforms. Edwards and Susmel (2003) investigated the time pattern of interest rate volatility in four Latin American countries,

\footnotetext{
${ }^{1}$ During the late 1980s and early 1990s the vast majority of the Latin American countries embarked on ambitious market-oriented reforms. The reform blueprint has come to be known as the "Washington Consensus." A number of authors have argued that this reform process has failed, and that the Latin American countries have grown at slower rates and have become more unstable. For an analysis of the reforms see, for example, Edwards (1995). See Stiglitz (2002) for criticism of the reform process. Edwards (2003) assesses the validity of Stiglitz's critique.
} 
and compared them to that of Hong Kong. Other recent studies on financial volatility and contagion in the emerging markets, including Latin America, are Karolyi and Stulz (1996), Eichengreen and Mody (2000), Forbes and Rigobon (2002), Bekaert, Harvey and Lumsdaine (2002a,b), Bekaert, Harvey and Ng (2002), Janakiramanan and Lamba (1998), Chakrabarti and Roll (2002), Edwards (2000) and Chen et al. (2002).

An important question, and one that we address in this paper, is whether stock markets have similar features in the emerging nations and in the advanced countries. The answer to this question is particularly germane to the current debate on the role of financial liberalization and macroeconomic instability in the emerging and transition economies. Some authors - including Krugman (2000) and Stiglitz (2002) - have argued that the emerging nations' financial markets are poorly developed and thus they do not function properly - e.g. in the way advanced countries' financial markets do. Under these circumstances, the argument goes, the emerging nations should not liberalize fully their capital markets; instead, they should impose some form of controls that regulate cross-border movements of portfolio capital.

More specifically, in this paper we analyze stock market cycles in a group of Latin American countries: We investigate the characteristics of stock market cycles in Argentina, Brazil, Chile and Mexico during 1975 - 2001, and we focus on the behavior of "bear" and "bull" markets, as defined by Pagan and Sossounov (2003), among others: "Bull" and "bear" phases of stock markets are identified with periods of a generalized upward trend (positive returns) and periods of a generalized downward trend, respectively. ${ }^{2}$ We make a distinction between the pre- and post-financial reform

\footnotetext{
${ }^{2}$ Two explanations have been put forward for the existence of bull and bear markets. One view, traditionally held by Keynes (1936), Galbraith (1954) and Shiller (1989, 2000) among others, is
} 
periods of the 1980s and 1990s, and we concentrate on the following characteristics of stock market cycles: Duration, amplitude and volatility. In addition, we analyze the extent to which returns depart from a triangular representation, and we investigate the occurrence of big expansions and contractions. The results from this cycle analysis are then used to compare the behavior of these four Latin American equity markets with those of two Asian nations - South Korea and Thailand -, as well as with those of the US and Germany.

The emerging stock markets analyzed in this paper - Argentina, Brazil, Chile, Mexico, South Korea and Thailand - represent a highly diverse sample: During the period under consideration they had different regulations regarding international capital mobility, different domestic supervisory systems and different exchange rate regimes. $^{3}$ Moreover, all of them, with the exception of Chile, faced serious crises during the last few years. This diverse data set, then, allows us to investigate the behavior of bull and bear markets under different institutional settings and under different external environments. We are particularly interested in addressing the following questions:

- Is it possible to (unequivocally) detect bull and bear markets in these Latin American and Asian countries?

- Do bull and bear markets in emerging countries behave similarly to those in the more advanced nations?

that major bull and bear markets are purely due to irrational "animal spirit." An alternative view (DeLong, 1992; Siegel, 1998) states that, although prices deviate from fundamentals in the short run, that is, in periods of months or a few years, in the long run - decades or even generationsproportional differences between market prices and fundamentals are kept within bounds. Under this interpretation, the major bull and bear markets reflect large shifts in consensus perceptions of fundamentals and expectations of the future.

${ }^{3}$ For details on the characteristics of the financial markets in the different countries and their refom processes see Bekaert and Harvey (2000). 
- Has stock market volatility been different across these countries? Has it changed through time? Is stock market volatility different in these countries than in the benchmarks represented by two advanced countries (the US and Germany)?

- How do bear and bull market cycles compare across the emerging markets in our sample? What do these comparisons tell us - if anything - about the effects of financial liberalization?

- Is it possible to explain the behavior of stock market cycles in our emerging markets using traditional models, including those in the "random walk" family?

The rest of the paper is organized as follows: In Section 2 we present the methodology used to identify bull and bear markets. In Section 3 we discuss the results of our cycle analysis, and we conclude that bear and bull phases have behaved in a significantly different way in emerging and advanced countries, but the differences seem to diminish in the post-financial liberalization period. In Section 4 we deal with the issue of concordance or synchronicity of the cycles across countries. The main findings in this section point at the increasing synchronicity of the stock markets in emerging countries, which move in a more parallel way during the 1990s than they did in earlier periods. Both the financial liberalization processes of the early 1990s and the financial crises of that decade seem to have contributed to this increased synchronicity. Section 5 complements the analysis in Sections 3 and 4 by looking at a specific characteristic of the cycle that allows for formal significance tests on the shape, and some predictability features, of the cycle phases. Finally, in Section 6 we present a brief summary of the results and some concluding remarks regarding the directions for future research that our paper opens. 


\section{Identifying Market Phases: A Non-Parametric Approach}

There are two main approaches to locating the expansionary / contractionary phases of the cycles in an economic variable. ${ }^{4}$ The first one advocates a parametric specification of the data generating process, where two different regimes are allowed, one that corresponds to the expansions - and therefore contains some type of upward trend -, and another one that corresponds to the contractions and therefore contains a downward trend. Examples of this approach are Goodwin (1993), Diebold and Rudebusch (1996), Kim and Nelson (1999), Hamilton and Lin (1993), Ramchand and Susmel (1998) and Maheu and McCurdy (2000). The second approach takes a nonparametric perspective and, instead of fitting a fully specified statistical data generating process, looks at the original data series in search for the specific features of the cycle. That is, this procedure looks for periods of generalized upward trend, which will be identified with the expansions, and periods of a generalized downward trend which will be identified with the contractions. The key feature of the analysis is the location of turning points, peaks and troughs, in the series. These turning points determine the different phases of the cycle, which can be subsequently analyzed. This method was first applied by Bry and Boschan (1971) to the analysis of business cycles, and has since been used by Watson (1994), Artis et al. (1996) and Harding and Pagan (2000, 2002) for business cycles, and by Pagan and Sossounov

\footnotetext{
${ }^{4}$ We do not comment on the advantages / disadvantages of one approach vs. the other. A fascinating discussion can be found in the exchange between Hamilton (2003) and Harding and Pagan (2003a,b). Alternative methods such as the use of long-returns - twelve month returns, for example - can also be used to focus on the medium term evolution of the stock market. However, the two methodologies we comment specifically attempt to locate the two types of phases - bull and bear phases - and thus directly address the analysis of stock cycles.
} 
(2003) and Gómez Biscarri and Pérez de Gracia (2002) for stock market analysis.

In this paper we opt for the nonparametric approach, as it allows for great flexibility in analyzing some important features of the stock market cycles. In addition, this approach allows us to compare the actual stock market cycle to parametric benchmarks, and to investigate issues related to predictability of the market.

We proceed as follows: We first identify the stock market phases in our six emerging countries by locating the peaks and troughs of a stock index. We then compute a battery of statistics for the phases in each country. This allows us to measure the main characteristics of Latin American stock markets and to compare their behavior to that of the Asian countries and of the US and Germany, the two countries we have chosen as "representatives" of the developed economies.

\subsection{Locating Peaks and Troughs}

The first step in the analysis of the cycle phases requires the location of the turning points - peaks and troughs that signal the change in the trend of the market - of the stock market index.

Throughout the paper, $p_{t}$ denotes the natural log of the stock price, $P_{t}$. A peak/trough in the series of stock prices is defined if $p_{t}$ is the highest/lowest in a window of width 8 months. ${ }^{5}$ That is, there is a peak at $t$ if

$$
\left[p_{t-8}, \ldots, p_{t-1}<p_{t}>p_{t+1}, \ldots, p_{t+8}\right]
$$

and there is a trough at $t$ if

$$
\left[p_{t-8}, \ldots, p_{t-1}>p_{t}<p_{t+1}, \ldots, p_{t+8}\right]
$$

\footnotetext{
${ }^{5}$ The results may be slightly sensitive to the choice of the window width. We use eight months, for a total width of the window of 16 months, as suggested by Pagan and Sossounov (2003).
} 
In order to ensure that we do not identify spurious phases we include the following four censoring criteria:

1) We eliminate turns within eight months of the beginning/end of the series.

2) Peaks or troughs next to the endpoints of the series are eliminated if they are lower/higher than the endpoints.

3) Complete cycles of less than sixteen months of total duration are also eliminated.

4) Phases of less than four months are eliminated unless the fall/rise exceeds $20 \%$ (the traditional rule of thumb for identifying a stock market cumulative movement as bullish or bearish).

After every censoring operation, alternation is enforced so that a peak will always follow a trough and viceversa. Alternation is achieved by taking the highest (lowest) of two consecutive peaks (troughs). In Section 3 we present the results obtained from applying this approach to dating bull and bear markets in six emerging markets as well as in the US and Germany.

\subsection{Stock Markets Cycles: Duration, Amplitude and Volatil- ity}

Once the bear and bull phases have been identified, we calculate a battery of statistics for each country. These statistics allow us to obtain some key information about the behavior of stock prices in each of the phases. This behavior can then be compared across countries and across phases, in search for relevant differences in stock market evolution. We use five different measures of cyclical behavior. Three directly relate to the shape of the phases of the cycle, while the other two focus on volatility within the cycle and on the existence of "big swings." 
As a preliminary step, we define a dummy variable, $S_{t}$, which takes the value 1 if there is a bull market at time $t$, i.e. if $p_{t}-p_{t-1}=\Delta p_{t}$ belongs to the bull market. ${ }^{6}$ Given that $S_{t}=1$ if there is a bullish market at $t$, we calculate two ancillary statistics: Total time spent in an expansion is $\sum_{t=1}^{T} S_{t}$ and total time spent in a contraction is $\sum_{t=1}^{T} B_{t}$, where $B_{t}=1-S_{t}$ is an indicator for bearish market. The Number of peaks (expansions) can be counted as NTP $=\sum_{t=1}^{T} S_{t}\left(1-S_{t+1}\right)-1$ (NTP is short for "Number of Trough to Peak") and the Number of troughs (contractions) is $N P T=\sum_{t=1}^{T} B_{t}\left(1-B_{t+1}\right)-1 .^{7}$ We also define the cumulated change over any expansion as $Z_{t}^{\text {bull }}=S_{t} Z_{t-1}+S_{t} \Delta p_{t}, Z_{0}=0 . Z_{t}$ contains the running sum of returns $\Delta p_{t}$ for bullish markets (similar definition with $B_{t}$ for bearish markets) with the sum reset to zero whenever $S_{t}=0$.

The five indicators of the phases of the market that we study are:

1) Duration (D): Average duration in months of expansions and contractions can be calculated as

$$
\widehat{D}_{\text {bull }}=\frac{1}{N T P} \sum_{t=1}^{T} S_{t}, \widehat{D}_{\text {bear }}=\frac{1}{N P T} \sum_{t=1}^{T} B_{t}
$$

2) Amplitude (A): Amplitude of the phases, in percentage, refers to the total return or total loss from the trough to the peak in a bull market or from the peak to the trough in the case of a bear market. Given that $p_{t}=\ln \left(P_{t}\right)$, the amplitude of any single phase can be simply calculated as the sum of returns $\left(\Delta p_{t}\right)$ over the complete

\footnotetext{
${ }^{6}$ Throughout the paper we refer to $\Delta p_{t}$ as "returns" though it more accurately corresponds to capital gains. Most of the parallel studies (Pagan and Sossounov, 2003; Aggarwal et al., 1999) use capital gains instead of returns, and we follow that same approach.

${ }^{7}$ Given that we only analyze complete phases, the initial and final phases are not counted. That is the reason for the " -1 " term in the formulas. However, if the initial and final phase are the same, then the adjustment does not apply to the other type of phase. For example, if the initial and final phases are bullish, the number of complete bull phases would be $N T P=\sum_{t=1}^{T} S_{t}\left(1-S_{t+1}\right)-1$ and the number of bear phases would be $N P T=\sum_{t=1}^{T} B_{t}\left(1-B_{t+1}\right)$.
} 
phase and therefore average amplitude corresponds to:

$$
\widehat{A}_{\text {bull }}=\frac{1}{N T P} \sum_{t=1}^{T} S_{t} \Delta p_{t}, \widehat{A}_{\text {bear }}=\frac{1}{N P T} \sum_{t=1}^{T} B_{t} \Delta p_{t}
$$

3) Volatility $(V)$ : We measure volatility by the average size of the monthly return in bullish and bear phases:

$$
V^{\text {bull }}=\frac{1}{\sum_{t=1}^{T} S_{t}} \sum_{t=1}^{T} S_{t}\left|\Delta p_{t}\right|, V^{\text {bear }}=\frac{1}{\sum_{t=1}^{T} B_{t}} \sum_{t=1}^{T} B_{t}\left|\Delta p_{t}\right|
$$

where $\left|\Delta p_{t}\right|$ is the absolute change of the log of stock prices.

4) Proportion of big expansions $\left(B^{+}\right)$and contractions $\left(B^{-}\right)$: The proportion of expansions and contractions that are bigger than 0.2 or smaller than -0.2 in percentage return is:

$$
\begin{aligned}
B^{+} & =\frac{1}{N T P} \sum_{t=1}^{T} I\left[S_{t}\left(1-S_{t+1}\right) Z_{t}^{\text {bull }}>0.2\right] \\
B^{-} & =\frac{1}{N T P} \sum_{t=1}^{T} I\left[B_{t}\left(1-B_{t+1}\right) Z_{t}^{\text {bear }}<-0.2\right]
\end{aligned}
$$

Given that $\left(Z_{t}^{\text {bull }}\right)$ and $\left(Z_{t}^{\text {bear }}\right)$ represent the cumulative return throughout the phase and up to time $t$, the summation term is calculating the value of the cumulative return at the end of the phase, that is, at the peak/trough. This is equivalent to the amplitude of the phase. The indicator function $I[a]$ is therefore counting the number of phases with amplitude bigger than 0.2 or smaller than $-0.2 .^{8}$

5) Excess Index (EX): This index captures deviations of returns in the bullish or bearish markets from a "triangle approximation." A pure random walk with no drift would produce triangular cycles, with excess measures not significantly different from zero in either bull or bear phases. Random walks with drift tend to produce bullish

\footnotetext{
${ }^{8}$ We use 0.2 as a measure of a "big" phase given that a $20 \%$ return / loss is the rule of thumb traditionally used by practitioners to identify the existence of a bull and bear market.
} 
phases with positive excess measure and bearish phases with negative excess measure, and this effect is accentuated when autocorrelation or conditional heteroskedasticity are allowed (See Pagan and Sossounov, 2003 for a detailed discussion). This excess index is calculated as:

$$
\widehat{E X}=\frac{(\widehat{C}-0.5 \widehat{A} \cdot \widehat{D}-0.5 \widehat{A})}{\widehat{D}}
$$

for both expansions and contractions. The first and second terms in the numerator approximate the area between the real path followed by the series (area $\widehat{C}$ ) and the triangular path (area measured by $0.5 \widehat{A} \cdot \widehat{D}$ ). The third term corrects for the discrete approximation used in computing the real path with $\widehat{C} .{ }^{9}$ The denominator makes the measure relative to the size of the phase. Figure 1 shows the possible shapes of the market phases and their relation to the sign of the EX index.

[Insert Figure 1]

\section{Bull and Bear Phases in Selected Emerging Mar- kets: Basic Results}

We use monthly data on stock returns for Argentina, Brazil, Chile, Korea, Mexico and Thailand. These data correspond to the S\&P/IFCG Emerging Market Indexes of Standard \& Poor's, formerly calculated by the IFC. ${ }^{10}$ The series run from 1975:12

\footnotetext{
${ }^{9}$ The average cumulated change $(C)$ for both phases of the cycle can be calculated as

$$
\begin{aligned}
\widehat{C}_{\text {bull }} & =\frac{1}{N T P} \sum_{t=1}^{T} Z_{t}^{\text {bull }}=\frac{1}{N T P} \sum_{t=1}^{T} \sum_{j=1}^{t} S_{j} \Delta p_{j} \\
\widehat{C}_{\text {bear }} & =\frac{1}{N P T} \sum_{t=1}^{T} Z_{t}^{\text {bear }}=\frac{1}{N P T} \sum_{t=1}^{T} \sum_{j=1}^{t} B_{j} \Delta p_{j}
\end{aligned}
$$

This measure is a discrete time approximation to the integral below (above) the bull (bear) market.

${ }^{10}$ These indexes, formerly calculated by the IFC, are dollar denominated price indexes of the stock markets in each country. We use the Global index and not the Investable, which is a narrower index
} 
to 2001:01, thus yielding a total of 302 observations spanning 26 years. ${ }^{11}$

Starting in the late 1980s, all six countries in our sample embarked on major financial reform processes that resulted in a liberalization of financial transactions and in growing domestic capital markets. An important question, and one that is at the center of recent criticisms of the reform process and the "Washington Consensus," is whether stock market cycles have exhibited an increase in amplitude and volatility i.e. increased instability - in the post-financial liberalization era. In order to address this issue, in the analysis that follows we make a distinction between the pre and post-liberalization periods. We follow Bekaert, Harvey and Lundblad (2001, Table 1) to date the beginning of each liberalization episodes. The following dates were used:

- Argentina: 1989

- Brazil: 1991

- Chile: 1992

- Mexico: 1989

- South Korea: 1992

- Thailand: 1988

For each country the turning points that define the phases were estimated using the methodology described in Section 2.1. Figure 2 contains the evolution of the stock indexes for each of the countries, where the bullish periods have been shaded to

that is only available from the 1990's on. The S\&P/IFC Global index represents the performance of the most active stocks in each market analyzed and attempts to be the broadest possible indicator of market movements, corresponding to at least $75 \%$ of total capitalization. For further information on these widely used indexes, consult www.standardandpoors.com.

${ }^{11}$ Data availability and comparability also dictated the final set of countries analyzed. Some local indexes, such as Brazil's Bovespa and Chile's IGPA, were available for longer periods, but we opted for using a uniformly calculated index to make comparison across countries more meaningful and not subject to the different methodologies used by the countries. Still, one would ideally use as long a series as possible. 
facilitate visual inspection. The graphs include four lines that signal the four major financial crises that affected emerging markets (EM's) in the 1990s: The Mexican crisis (identified in December 1994), the Asian crisis (September 1997), the Russian crisis (August 1998) and the Brazilian crisis (January 1999).

\section{[Insert Figure 2]}

The dates of the estimated peaks and troughs for each country, along with those of the US are shown in Table 1. The table has been arranged so that the lining up of peaks and troughs can be easily examined visually. The first finding that comes from inspection of both the graphs and the dates in Table 1 is that all recent major financial crises in our sample erupted several months into the bear phase. Moreover, in some cases the crisis erupts very close to the end of a bear cycle. This is, for instance, the case of the December 1994 Mexican crisis, which happened two months before the trough in February 1995 and after the country had spent a whole year in a bear phase. Korea and Thailand had spent a considerable time in a bear phase (three and one and a half years, respectively) before the Asian crisis exploded. The markets in both countries took almost an additional year to bottom out and start the recovery. In Brazil, the January 1999 crisis coincides with the trough of an 18 month bear market. Argentina, finally, reached a peak in February 2000, which means that by the time of the crisis in late 2001 the Argentine market had spent almost two years in a bear phase. ${ }^{12}$ This finding, however, should be taken with a grain of salt. Indeed, although our results are highly suggestive, they do not necessarily imply that bear markets are good predictors of currency and financial crises. Answering this question

\footnotetext{
${ }^{12}$ Notice that this is also the case for earlier crises, such as the Mexican crisis of August 1982.
} 
fully is, however, beyond the scope of this paper. ${ }^{13}$

[Insert Table 1]

Table 2 presents results for the five statistics calculated for both the bull and bear markets in our six EM's. Additionally, we include the values of these statistics for the US and German stock markets. ${ }^{14}$ The Table consists of three panels, that present the results of the full sample, and the results for the pre and post-reform periods. ${ }^{15}$ The data on the US and Germany in Panel B correspond to the 1975-1989 period; those in Panel C are for 1990-2001.

\section{[Insert Table 2]}

The results for the two subperiods are particularly interesting, and indicate that, contrary to what the critics of the market oriented reform processes have argued, the degree of equity markets instability has declined in our four Latin American nations after the crises. The main results in Table 2 may be summarized as follows:

Duration: After the financial reforms of the late 1980s and early 1990s, average duration of bear markets declined in all four Latin American countries, as it did in Thailand. In Korea, on the other hand, average duration of bear markets increased in the post reform period. The duration of bull markets declined in the post-reform period in four of the six emerging markets - the exceptions being Argentina and Mexico.

\footnotetext{
${ }^{13}$ The crisis early warnings model developed by Goldman Sachs (2002) does include a decline in the stock market as a useful leading indicator.

${ }^{14}$ These results correspond to our own calculation for the US market during the period 1975:01 to 2000:12, using the turning points estimated by Pagan and Sossounov (2003). In the case of the German market, the results correspond to the period from 1970:01 to 1999:11 estimated by Gómez Biscarri and Pérez de Gracia (2002).

${ }^{15}$ The data for the different emerging markets have been divided by using as the split date the peak or trough that is the closest to the liberalization date, so that we keep complete phases both in the pre and post-reform periods.
} 
As a consequence, in the most recent (post-reform) period duration of bear markets continues to be higher and duration of bull markets continues to be lower in all six emerging markets than in the US.

Amplitude: The amplitude of both bull and bear phases has been significantly larger in the emerging countries than in the developed nations. Emerging stock markets seem to offer a significant premium, or excess return, during expansions, that compensates for the big losses during contractions, and for the substantially higher volatility. For the emerging markets there appears to be an ordering of countries, where those with bigger gains are also those with bigger losses. This phenomenon is also present in the case of European nations analyzed by Gómez Biscarri and Pérez de Gracia (2002). The figures for the emerging countries are staggering, though: During the 25 year period, average gains during bullish periods range from $79 \%$ (Korea) to $142 \%$ (Argentina); average losses during bearish periods go from $68 \%$ (Korea) to $123 \%$ (Argentina). ${ }^{16}$

Although amplitude of both bull and bear markets continues to be very high in comparison to the US and Germany, it has declined in all four Latin American countries during the post-reform period. In the two Asian countries, on the other hand, the amplitude of bear phases goes up dramatically in the post-reform period, mostly because of the influence of the Asian crises. Amplitude of bull phases in Asia is similar in the pre- and post-reform periods.

Volatility: Within each phase volatility is generally much larger in the emerging markets than in advanced countries. This is the case both in the pre- and post-reform

\footnotetext{
${ }^{16}$ Note that when the returns are significantly large in absolute value, using $p_{t}-p_{t-1}=\ln \left(P_{t}\right)-$ $\ln \left(P_{t-1}\right)$ as a measure of return will yield different results from using $\frac{P_{t}-P_{t-1}}{P_{t-1}}$, and a loss bigger than $100 \%$ is actually possible. For example, if $P_{t}=25$ and $P_{t-1}=100$, the first formula results in a $139 \%$ loss whereas the second results in a $75 \%$ loss.
} 
periods. However, in the post financial liberalization period, volatility has declined significantly in every Latin American country in our sample. Notice that the value of volatility is smaller in the second subperiod for bull phases in all four Latin American countries and for bear phases in Argentina, Chile and Mexico. In the case of Asian countries, on the other hand, their markets evolved in the opposite way, and after 1990 their stock market fluctuations seem to behave more like those of pre-1990s Latin America: Volatility of both bull and bear phases is larger in post-reform Korea and Thailand than before financial liberalization.

The increased volatility of bear phases in the second subperiod for Brazil, Korea and Thailand is mostly attributable to their own, very profound and unique, crises, and not to increased general instability: Notice that no volatility increase happened in the bull periods of Brazil or in either phase in Argentina, Chile and Mexico. Consequently, these findings cast some doubt on the statements by critics of financial liberalization which point at a generalized increase in volatility following the opening of emerging capital markets.

Excess Index: As reflected in Table 2, the values of the $E X$ index for our emerging countries differ substantially from those of the US or Germany. The EM's tend to present widely varying $E X$ indexes in both bull and bear phases. The signs are not always positive and negative respectively, but some present bull phases with negative value of the $E X$ index and bear phases with positive value. This evidence on the $E X$ index is in line with one of the key findings in Pagan and Sossounov (2003): Stock market phases do not look triangular, as it would be implied by a simple random walk. Instead the beginning and end of both the bull and bear phase display some "acceleration," by which the large returns or losses are not distributed evenly across 
the phase, but are instead concentrated close to one of the turning points. It would be tempting to automatically identify these nonzero values of the $E X$ index with a departure from the random walk behavior and therefore from unpredictability, as it is done by Pagan and Sossounov. However, Gómez Biscarri and Pérez de Gracia (2002) show that this is not exactly correct. Simulations in their paper prove that a random walk with drift but no autocorrelation - and therefore, unpredictable beyond the regular market return - generates cycles with $E X$ measures significantly different from zero in both phases. This implies that our results for the EM's could be consistent with stock markets following random walks with drift, with or without autocorrelated returns. If one wants to use the $E X$ index to test for the existence of some predictability in the market or for departures from the random walk behavior the values of the index that are consistent with statistical models of unpredictable returns need, thus, to be calculated case by case. We take up this task, which yields important conclusions, in the last section of the paper.

Big Expansions and Contractions: The $B^{+}$and $B^{-}$suggest that during the postreform subsample most bear phases have been "bigger" than in the pre-reform period. Indeed, as these indexes show, after 1990 all contractions of Latin American and Asian stock markets have been large, except one in Chile, the country whose cycles look more similar to those of the developed economies. We attribute this effect mostly to the effect of the Asian crisis - notice that there are fewer years in the post-reform period, and thus fewer bear phases - and not to the increased instability: As we have seen in the results on amplitude and volatility the evidence favors a generalized reduction in instability, once the effect of the bear market caused by the Asian crisis is isolated. 


\section{Financial Reforms and Stock Market Cycles Across Countries}

In this section we extend our bull and bear markets analysis and look at the joint evolution of the six emerging stock markets investigated above. We are particularly interested in understanding whether stock market phases tend to "coincide" in time across emerging countries. That is, we try to identify whether, at a given moment in time, stock markets in EM's are in the same phase of the stock market cycle. We also try to ascertain whether this comovement or concordance across equity markets has intensified during the post-reform period. Since during the late 1980s and early 1990s these countries relaxed their controls on international capital mobility, we would expect an increase in the degree of comovement across their equity markets. ${ }^{17}$

The rest of the section is organized as follows. First, we provide a simple analysis that compares the timing of the peaks and troughs of the stock market series across time. This analysis shows how coincident in time the turning points have been across our Latin American and Asian countries. Then we look more formally at the long run coincidence of the phases. We provide statistical measures of the degree of bilateral coincidence of bull and bear markets across countries throughout the entire sample. Finally, we show a dynamic measure of concordance that tracks the evolution of the synchronicity of cycle phases during the most recent post-reform years. This latter measure allows us to comment on whether the stock markets of our EM's have become more concordant over time.

\footnotetext{
${ }^{17}$ The fact that emerging markets' equities are considered to be an "asset class" provides greater support to the hypothesis that comovements across these countries should have increased in the post-reform period.
} 


\subsection{Peaks and Troughs in Bull and Bear Phases}

In Table 1 we presented the peaks and troughs identified for the equity cycles of our four Latin American nations, the two Asian nations and the US. These data show that before the financial market liberalizations of the late 1980s and early 1990s the peaks and troughs of our six emerging countries were not aligned at all. Furthermore, they were not aligned with those identified for the US. In fact, all six countries seemed to follow widely differing patterns before 1990. For example, Argentina's phases from 1975 to 1987 do not have a single turning point in common with, or within a seven month window of, those of Brazil. The same holds true for the rest of the countries: Peaks and troughs do not coincide in time until the US stock market crisis of 1987, when three of the EM's - Argentina, Brazil and Mexico - present a trough almost simultaneously to that in the US. It is slightly surprising that it is the troughs that coincide in time, and not the peaks. This leads to think that US investors pulled out of both the US and international markets at the time of the crisis, regardless of whether the markets were going up or down, and when the market recovered, capital flowed back into all four markets simultaneously. ${ }^{18}$ After the crash, turning points become misaligned again until 1990 when, coinciding with the worldwide recession, Brazil, Chile, Korea, Thailand and the US present a trough.

After 1990, a time when the countries in our sample had either initiated, or were about to launch their reforms, individual cycles begin to exhibit evident comovement. With the exception of Korea, that does not present a cycle in 1996-1997, the other

\footnotetext{
${ }^{18}$ The literature on the effects of the 1987 US stock market crisis is by now abundant. King and Wadhwami (1990), Lee and Kim (1993) and Choudhry (1996) are among the earlier contributions that document an increase in world stock market comovements after the crisis. Forbes and Rigobon (2002) review some of those contributions in the context of contagion of financial crises.
} 
five countries all present very similar patterns, with peaks around the second quarter of 1992, one during 1994, one in late 1997 (around the time of the Asian crisis), and a final peak in early 2000. Troughs also come almost simultaneously in late 1992, early 1995 (after the peso crisis in Mexico) and a final one in late 1998, following the Russian crisis. Only Brazil seemed to be affected by its own crisis: It is the only country whose stock market did not bottom out in September 1998 at the time of the LTCM crisis - as did all the others -, but kept its downward slide until January 1999, when it started to recover after the devaluation of the real.

It is interesting to note that the different financial crises of the 1990s had dissimilar effects across EM's. According to the data, the Mexican crisis affected Argentina and Brazil, but it did not affect Chile, Korea or Thailand. In contrast, all six countries were significantly affected by the collapse of the Asian markets in 1997 . We do not have enough data on the Russian equity market in order to carry a similar analysis of the effects of that crisis on Russia's own market. However, it can be seen that the Russian crisis of August 1998 did not have any noticeable effects in the EM's in our sample. In fact, it seems that the crisis marked the beginning of the recovery after the Asian flu, rather than sending the markets into another downslide. As mentioned above, the crisis in Brazil did not spillover to other markets. ${ }^{19}$

These findings suggest that in the post-reform period, emerging equity markets or at least the emerging markets considered in this paper - were becoming significantly more integrated with each other. We turn now to a more formal analysis of the concordance or synchronicity of the stock market phases in our EM's.

\footnotetext{
${ }^{19}$ Notice that we do not pretend to have established statistical causality.
} 


\subsection{Concordance of the Cycle Phases: Are the Cycles Aligned?}

In order to analyze formally the extent of the comovements of the stock market data in our six emerging countries, we use an index of synchronicity of the bull and bear phases which allows us to compare statistically the degree of alignment or concordance of the cycle phases in two or more countries. This index of phase concordance is the concordance index $(C I)$, used in Harding and Pagan (2000, 2002). This index is calculated, for countries $i$ and $j$, as

$$
C I_{i j}=\frac{1}{T} \sum_{t=1}^{T}\left[S_{t}^{i} \cdot S_{t}^{j}+B_{t}^{i} \cdot B_{t}^{j}\right]=\frac{1}{T} \sum_{t=1}^{T}\left[S_{t}^{i} \cdot S_{t}^{j}+\left(1-S_{t}^{i}\right) \cdot\left(1-S_{t}^{j}\right)\right]
$$

where $S_{t}^{i}=1$ identifies a bullish market at time $t$ in country $i$ and $B_{t}^{i}=1$ identifies a bearish market at time $t$ in country $i$. This index calculates the number of the $T$ periods for which the two countries are in the same phase, either bull or bear, and averages out over the $T$ periods. ${ }^{20}$

The values of the $C I$ range from zero (perfect misalignment of phases) to one

\footnotetext{
${ }^{20}$ This index is, in our view, superior to cross-correlations of returns. Indeed, cross-correlations have four main limitations. First, unconditional cross-correlations of returns are subject to sectorial composition of the stock indexes and do not account for movements in fundamentals (see Wolf, 1996). Second, the use of simple cross-correlations would be affected by the existence, not infrequent in the case of stock market movements, of outliers. By identifying the phases with a binary variable, we avoid the artificial increase in cross-correlation that results from extremely big returns. Third, given that returns have an upward drift, the correlation of returns tends to be positive and statistically significant due to that trending behavior. Given that we are not interested in the concordance or correlation per se, but on the concordance of the innovation to the return process - which expresses the way new information affects returns - the correlation would have to be computed with the estimated residuals of the return process, thus being subject to the statistical process that returns are assumed to follow. Fourth, the behavior of volatility or of higher moments of the returns would also affect the cross-correlation measure of the concordance of cycles, whereas the $C I$ is invariant to the underlying distribution of returns once the phases have been identified. Finally, we are not interested in forecasting returns or in the short term movements of the market: Our main concern is to calculate the concordance of phases in the stock markets, and these phases correspond to medium to long run movements. Using cross-correlations of returns would put too much emphasis on short term movements. The methodology used to construct the phase indicators guarantees that we focus on the medium term trends of the stock market. For these five reasons we believe that the $C I$ provides a more intuitive measure of the concordance of the cycle phases, and, given the objective of our study, a more correct one.
} 
(perfect alignment). However, given that random walks with drift generate cycles with longer and bigger bullish phases than bearish phases, it is clear that even if the shocks to the random walks are perfectly independent, the $C I$ will be slightly bigger than 0.5 , the value we would obtain if the phases were purely random draws from a 50:50 Bernoulli distribution. Therefore, a formal significance test requires us to calculate the critical values in a case by case fashion. Thus, we simulated independent random walks with the same drift, return autocorrelation and variance as the series in each country. Then we calculated the simulated distribution of all bilateral $C I$ 's and found the interval contained between the $2.5 \%$ and $97.5 \%$ percentiles. When the empirical index is outside of that confidence interval, the hypothesis that the two series have phases that come from independent processes can be rejected. This gives evidence of significant concordance of stock market behavior in those two countries. ${ }^{21}$

Table 3 presents the $C I$ 's for the different pairs of countries. In Table 4 and for comparison purposes we include the simple cross correlations of returns, for the same sample period. Each table includes three panels. The first panel contains the values of the indexes for the full sample. The second and third panels split the sample into two subperiods: Given our discussion above, we analyze the concordance of market phases before and after financial liberalization, although given that the dates of liberalization are slightly different for the different countries, we use now

\footnotetext{
${ }^{21}$ Notice that this is also the case for the coefficients of correlation of returns: Traditional critical values for significance of the coefficient of correlation between two series are biased downward for time series with a drift and autocorrelation in returns. Thus, the significance test would have to be performed on the innovations to the two series, estimated by first fitting a statistical model to the returns. Given the higher dependency that these estimated innovations would have on the specific model chosen to fit the returns, we have opted against offering a significance test for the simple coefficients of correlation. However, we still use their evolution in time and their magnitude to compare the results to those of the $C I$ and of the $R C I$ (next subsection).
} 
1990 as the common splitting date.

\section{[Insert Tables 3 and 4]}

The values of the $C I$ for the full sample (1975-2000) are not particularly interesting; they are in general larger than 0.5 , but most of them are not significant. The exceptions to this result are the pairs Argentina-Mexico, Chile-Mexico and Thailand with Korea and Mexico. ${ }^{22}$ However, once we split the sample into the pre-1990 and the post-1990 years, the evidence changes. For the pre-1990 period only Chile and Mexico, among our Latin American countries, show evidence of a significant concordance. Interestingly enough, Thailand is the only country showing significant comovements, negative in the case of Brazil, with more than one country. In spite of this, however, we interpret the overall evidence in Panel B of Table 3 as suggesting quite strongly that before 1990 concordance of cycles among EM's was rather weak and generally non significant.

Panel C in Table 3 presents the CI's for the post 1990 period. As may be seen, during this period the Latin American equity markets become significantly concordant: In the second subperiod, Argentina shows positive concordance with Brazil and Mexico, and, weaker, with Thailand. Brazil shows concordance with Mexico and Chile. Chile, on the other hand, sees the concordance of its market phases increase with respect to Brazil and Korea, but decrease with respect to Mexico. Notice that after 1990 evidence for concordance of phases in the Thai stock market weakens

\footnotetext{
${ }^{22}$ The values of the $C I$ 's are parallel to those of the simple coefficients of correlation. Estimated correlation coefficients tend to be positive and small. The highest values correspond to the pairs of countries with higher bilateral $C I$, and, as we have highlighted in the table, the $C I$ 's that are statistically significant correspond to the highest values of the simple correlations, those above 0.223. Thus, conclusions of the static analysis would not change much were we to use the $C I$ or the correlations of returns.
} 
significantly.

These results suggest that it is possible to distinguish three groups of countries during the post reform period. The first one is a closely linked group formed by Argentina, Brazil and Mexico. Notice that all three of these countries faced crises during this period, and throughout most of the period under consideration they were not classified as investment grade countries by the rating agencies. The second group is formed by Chile and Korea, that have become more concordant with each other, but less concordant with other countries. While Korea faced a massive crisis in 1997, Chile did not have one during this period. Nevertheless, both of these countries were investment grade during most of the 1990-2000. Finally, Thailand doesn't seem to fit with any of the other two groups. During 1990-2000 its concordance with all other countries, except perhaps with Argentina, declines. It is interesting to note that, although the $C I$ is quite high for all US-other country pairs, it is only statistically significant for Mexico and Argentina. This indicates that while the emerging markets have become significantly more integrated among themselves, the degree of integration with the US equity market has not necessarily proceeded at the same pace.

We now analyze whether a more dynamic analysis of the time evolution of the concordance indexes supports a story of increased market concordance.

\subsection{Is there a Tendency Toward Further Concordance?}

Instead of focusing on two subperiods - pre- and post-liberalization - we analyze whether the degree of concordance has tended to change - gradually, perhaps through time. More specifically, we are interested in finding out if after the reforms there is a tendency towards an increased degree of concordance across countries. In 
general, one would expect that financial reforms that open up domestic financial markets - even if they do so partially - would increase the extent of market comovement across countries. This would be particularly the case if the countries in question are considered to form a (semi) homogeneous "asset class." Indeed, even if restrictions to capital mobility are only partially lifted, we would expect a (gradual) increase in the $C I$ through time. In order to address this issue we calculate a set of rolling $C I$ 's ( $R C I$ 's), using a window of width 50 . That is, we calculate the series of $R C I$ 's as

$$
R C I_{i j}^{\tau}=\frac{1}{50} \sum_{t=\tau-49}^{\tau}\left[S_{t}^{i} \cdot S_{t}^{j}+B_{t}^{i} \cdot B_{t}^{j}\right] .
$$

The results obtained for $R C I_{i j}^{50}$ to $R C I_{i j}^{302}$ are plotted in Figures 3-6. ${ }^{23}$ For comparison purposes, in these figures we also include the evolution of rolling coefficients of correlation of returns, calculated as:

$$
R \rho_{i j}^{\tau}=\frac{\sum_{t=\tau-49}^{\tau}\left(r_{i, t}-\bar{r}_{i}\right)\left(r_{j, t}-\bar{r}_{j}\right)}{\sqrt{\sum_{t=\tau-49}^{\tau}\left(r_{i, t}-\bar{r}_{i}\right)^{2}} \sqrt{\sum_{t=\tau-49}^{\tau}\left(r_{j, t}-\bar{r}_{j}\right)^{2}}}
$$

where $r_{i, t}$ corresponds to the return $\Delta p_{t}$ for country $i$ during period $t$ and $\bar{r}_{i}$ is the average return for country $i$ during the 50 periods in the rolling window.

[Insert Figures 3-6]

The $R C I$ 's and $R \rho$ 's give information about the evolution in the behavior of concordance in the emerging countries in our sample. A trend upward (downward) in the index signals increased (decreased) stock market concordance.

\footnotetext{
${ }^{23}$ Formal significance testing should be performed by simulating the distribution of the critical values. We simulated critical values for the $R C I$ 's by generating series with the estimated drift and return autocorrelation of each of the four countries, calculating the $R C I$ 's for each simulated series and taking the $2.5 \%$ and the $97.5 \%$ percentiles of the simulated values in each period. Given that the drifts for the different countries are similar, the confidence bands for the $R C I$ for each country pair turn out to be also similar, with 0.72 being the upper critical value. For simplicity, we do not include the confidence bands in the graphs, although these are available upon request.
} 
The rolling cross correlations of returns presented in these figures were never substantially high, in either direction, during the first years of the sample. The trend reverses, however, after the early 1990s, when an increase in correlations is evident, especially among Latin American countries. Concordance of cycle phases has also tended to be quite high in the years after liberalization; indeed, this index moves close to one in the last periods for a number of country-pairs. There are some differences in the evolution of both measures, though, that make the two complementary rather than redundant. For example, Brazil and Chile during the early 1980s presented a very significant negative concordance of cycles, whereas correlations gave no evidence of a significant relationship. Another interesting difference appears in the case of Chile with the other three Latin American countries. Return correlations start to trend up in the mid 1990s, whereas the concordance of phases only starts to increase well after the Asian crisis. Consequently, both measures tell the same story about the high concordance of Latin American markets after financial liberalization, but the dynamic behavior identified is rather different. We believe that the main limitation of cross correlations in our setting is that the abnormal returns during the crises in the second half of the 1990s generate large "outliers" that tend to blur the real concordance of the behavior of the stock markets in the medium term.

The $R C I$ 's in Figures 3-6 suggest that equity markets in our Latin American countries have become increasingly concordant in the last few years. This trend has been persistent, as it is the case of Argentina, Brazil, Mexico, or it has had ups and downs for the pairs Chile-Argentina and Chile-Mexico. The case of Chile - the only country in the sample that did not suffer a currency crisis during the post reform period - is particularly interesting. As mentioned above, the $R C I$ of Chile with 
Argentina and Mexico drops significantly at the time of the Tequila crisis, reflecting the fact that Chile did not suffer from Mexican-originated contagion (Edwards and Susmel, 2003), and it stays low through the Asian crisis. In both cases the RCI's recover pre-crisis levels by the end of the sample, thus signaling that the Chilean economy has indeed become highly concordant with its close neighbors but at the same time it is somehow insured against contagion from crises that affect its neighbors.

Korea and Thailand show high concordance of states and correlation of returns with each other only in the last two years. Thus, the Asian flu did not bring about a higher comovement of the two markets, which up to that moment seemed to have evolved quite independently from each other and also with respect to Latin American countries. After experiencing a decline during the latter part of the 1980s and early 1990s, the RCI's for Korea end up being well above significance levels with respect to Argentina, Brazil and Chile, although they never reach levels similar to those of the Latin American countries among themselves. Thailand, on the other hand, does not show signs of concordance with any Latin American country except, maybe, Chile. It did show significant concordance in the earlier years - before the crisis, around the liberalization dates -, but this concordance has in fact decreased in recent periods.

Our results therefore show strong concordance of Latin American stock markets and a clear tendency towards stronger concordance in the most recent years, especially after financial liberalization. Korea and Thailand have become less concordant with respect to all the other countries although Korea seems to be recovering and entering in phase again with the Latin American countries in the most recent years.

These findings suggest that liberalization processes have indeed contributed to a much stronger comovement of the stock markets in the emerging countries - both in 
the short term, as measured by the correlations of returns, and in the medium term, as measured by the concordance indices -, and this result is quite consistent across the board. The financial crises have introduced some noise in these relationships, especially around the years of the Asian flu. After the effects of the Asian crisis died away - the Russian and Brazilian crisis did not have a similar effect - all Latin American countries and Korea give evidence of strong comovement, whereas Thailand seems to have become detached from the rest of the group. These results are in contrast with studies such as Wolf (1996), that claim that Asian equity markets have experienced a big increase in the degree of comovement during the 1990s whereas comovements for the Latin American countries remained small even after the reforms.

\section{The Shape of Emerging Cycle Phases: A Simu- lation Exercise}

One of the advantages of our approach is that it allows us to compare the actual stock market cycle to benchmarks characterized by random walk-type models. As pointed out above, if the true data generating process is indeed a random walk, the cyclical behavior would follow a triangular path. If, however, empirical cycles depart from those generated by a random walk, the cyclical pattern could take a number of alternative forms. Figure 1 depicted the four possible shapes of the market behavior depending on whether the market is bullish or bearish and on the sign of the $E X$ index. ${ }^{24}$

\footnotetext{
${ }^{24}$ In theory, all five cycle characteristics discussed in Section 2 could be used in this way to test some statistical model. However, it turns out that most statistical models can replicate fairly well all measures except for the excess index. This index, therefore, turns out to be the one that can most successfully be used for a formal testing of whether a statistical model is consistent with observed market behavior.
} 
In order to gain a deeper understanding of whether stock market phases depart from what random walk-based models would imply, we perform a simulation experiment. ${ }^{25}$ First we fit three statistical models of returns to all six of our markets for the three different subperiods - full sample, 1975-1989 and 1990-2001. These three models differ with respect to the behavior of the volatility of the error term. The three models estimated are: ${ }^{26}$

I) A random walk with drift and $\mathrm{AR}(1)$ increments

$$
\Delta p_{t}=\mu+\rho \Delta p_{t-1}+\sigma \varepsilon_{t}, \varepsilon_{t} \rightarrow \operatorname{nid}(0,1)
$$

II) A random walk with drift and $\mathrm{AR}(1) / \mathrm{GARCH}(1,1)$ effects

$$
\begin{aligned}
\Delta p_{t} & =\mu+\rho \Delta p_{t-1}+\sigma_{t} \varepsilon_{t}, \quad \varepsilon_{t} \rightarrow \operatorname{nid}(0,1) \\
\sigma_{t}^{2} & =\alpha+\beta u_{t-1}^{2}+\gamma \sigma_{t}^{2}, \quad u_{t}=\sigma_{t} \varepsilon_{t}
\end{aligned}
$$

III) A random walk with drift and $\mathrm{AR}(1) / \mathrm{EGARCH}(1,1)$ effects

$$
\begin{aligned}
\Delta p_{t} & =\mu+\rho \Delta p_{t-1}+\sigma_{t} \varepsilon_{t}, \quad \varepsilon_{t} \rightarrow \operatorname{nid}(0,1) \\
\ln \sigma_{t}^{2} & =\phi_{0}+\phi_{1} \varepsilon_{t-1}+\phi_{2}\left|\varepsilon_{t-1}\right|+\phi_{3} \ln \sigma_{t-1}^{2}
\end{aligned}
$$

Note that all three models include the possibility of returns being autocorrelated, and therefore if there is indeed some autocorrelation in the market, it will show up in the coefficient $\rho{ }^{27}$ We are therefore interested in detecting features that may point at predictabilities beyond that of a simple autocorrelation of returns.

\footnotetext{
${ }^{25}$ Our procedure is a parametric bootstrap where we simulate returns from the implied distribution it falls under the category of parametric bootstrap (Maddala and Li, 1996).

${ }^{26}$ These three models have been chosen because they are the ones that best replicate the features of the empirical cycles (see Pagan and Sossounov, 2003). More complicated models such as regimeswitching models or processes with stochastic volatility have been analyzed, but their performance in fitting the features of the data is much poorer than that of the three simpler models we consider.

${ }^{27}$ Strictly speaking, therefore, if $\rho \neq 0$ the three models are not random walks. We do not comment on the values of the estimated coefficients. Across countries and for the three different estimation periods, the values of $\rho$ differ substantially, some of them being statistically significant.
} 
Second, we simulated 1,000 series of returns - of length equal to the number of observations available in each country's stock market series - for all six countries, given the estimated parameters for the above three models. We calculated the excess measures for each of the 1,000 simulated series and constructed the simulated distribution of the excess measure under each of the three models. From these simulated distributions we find the $2.5 \%$ and $97.5 \%$ critical values.

Third, we compared the values of the empirical excess measures estimated for the original series of the four countries (fourth and tenth rows in Table 2), with the critical values that result from simulating the stock market with the estimated parameters of the three models. ${ }^{28}$ The results of the simulated critical values for the different countries and models appear in Table 3.

\section{[Insert Table 3]}

These results indicate that all three statistical models fail to replicate correctly the value of the $E X$ index for all of our countries. Moreover, this failure is not symmetric across time periods or across phases. In fact, the divergence between the $E X$ indexes implied by the three random walk models and the computed $E X$ indexes is more noticeable during bull markets in the 1975-1989 period, and during bear markets in the 1990-2001 period.

Period 1975-1989: Indeed, the shape of bull phases during the 1975-1989 period is only well replicated for Korea, for which an EGARCH specification seems coherent with the empirical value of the index. However, for the other five countries the empirical value of the $E X$ index is significantly outside the simulated confidence

\footnotetext{
${ }^{28}$ All parameter values are available upon request. We omit them from the exposition in order to simplify the discussion.
} 
interval. In the case of Argentina, Brazil, Mexico and Thailand the shape of the bull phase tends to be like that in Figure 1B, where the market accelerates as the peak is being reached. In the case of Chile, the shape corresponds to that in Figure 1A, so the bigger returns are located at the beginning of the expansion. Bear phases, on the other hand, are correctly replicated for Argentina and Chile, but not for the two Asian countries - where bear phases resemble Figure 1D, with the big negative returns present at the beginning of the phase - or for Brazil and Mexico - where the phases behave as in Figure 1C, with an acceleration of the negative returns at the end of the phase.

Period 1990-2001: It is interesting to note that in this post liberalization period bull phases are well accounted for in the cases of Brazil, Chile, Korea and Mexico. In other words, bull phases of most emerging markets become consistent with simple statistical models of returns. Argentina and Thailand, however, still show some departures - the phases in both countries having the shape in Figure 1B - but the magnitude of the departure is smaller than in the period prior to liberalization. Bear phases present another regularity. In all cases - except Thailand - the phases after liberalization resemble Figure 1C: Large negative returns are present at the end of the bear phase, when the market is reaching the bottom of the cycle. This would be in line with the finding that the troughs tended to come a few months after the onset of the different financial crises, and thus provide with some evidence in favor of the usefulness of the $E X$ index in characterizing stock market behavior.

It seems, therefore, that with financial liberalization the behavior of the stock markets in emerging economies became more in line with what would be implied by simple models of stock market behavior - compatible with market efficiency or 
with some mild predictability. Gómez Biscarri and Pérez de Gracia (2002) also found some departures from the random walk excess measure in their analysis of European markets. In the case of Europe, departures were much smaller in magnitude and nonsignificant in most of the cases, but they were of a similar form to those we detect in the post-liberalization period for emerging countries. This also reinforces the finding in Section 3, where emerging stock markets were found to become more similar to those in developed economies after financial liberalization.

These results are also important for they point at a feature of stock market predictability that cannot easily be accommodated by traditional statistical models and that is not apparent from a casual examination of the series. Figure 2 does give some evidence of this result, but it is always difficult to disentangle the part of the departure from the triangle path that could be due to the drift of the random walk, or to variance effects. More complicated processes, such as stochastic volatility or regime switching models also fail to replicate this effect, plus they do a very poor job in replicating some of the other features (see Pagan, 2002, Pagan and Sossounov, 2003, and Gómez Biscarri and Pérez de Gracia, 2002). In the case of a two regime switching model (Hamilton, 1989), for example, the two regimes are indeed identified with the bull and bear phases, but no distinction is made between the behavior of the series during the first and last months of each of the phases, a feature that, as we have seen, appears in the data analyzed.

\section{Conclusions}

The possible consequences of financial liberalization processes in Latin America continue to be a subject of discussion and controversy. For some researchers, the alleged 
short term increase in instability may prevent countries from reaping the longer term gains. ${ }^{29}$ Consequently, the analysis of the medium term effects of financial opening and its relation with induced instability becomes a key aspect of the broad research project of understanding financial market transitions in emerging economies. In this paper we have analyzed some of the implications for stock market behavior of the financial liberalization process in Latin America and Asia. In order to emphasize the medium term effects, our analysis is focused not on simple returns but on the cycles of the stock market, which characterize the stock market behavior over longer periods. We analyzed the characteristics of market cycles - distinguishing the bull and bear phases - for four Latin American and two Asian countries. In addition to identifying the bull and bear phases in the stock price cycles we measured several characteristics of the phases, such as duration, amplitude, volatility within the phase and the shape of the cycle.

We placed special emphasis on the possible differences in behavior caused by the financial liberalization processes. We found that, while the characteristics of the stock market cycles in emerging markets differ quite markedly from those in developed economies - namely, bull phases tend to be shorter, bear phases are longer, amplitude and volatility of both phases is significantly higher than in developed markets -, the financial liberalization processes have contributed to making Latin American stock markets more similar to those in more developed economies. Latin American stock markets after liberalization are less unstable: Volatility is lower in both cycle phases and the amplitude of the phases has been significantly reduced, coming closer to that of developed countries. This is not the case, however, for Asian countries, that

\footnotetext{
${ }^{29}$ For example, Aizenman (2002) examines the apparent trade-off between the short-term induced instability and the long-run contribution to growth caused by financial opening.
} 
seem to have been affected too intensely by the financial crisis of late 1997 . There is evidence that these countries, especially Korea, are recovering their stability in the most recent years, but it is still too early to assess the medium-term consequences if any - of the crisis.

We also calculated concordance indexes for the countries in the sample, in an attempt to detect whether the countries tend to be in the same phase of the stock market cycle or not, and whether there has been a tendency for concordance to increase over time. We showed that the behavior pre and post financial reform has changed significantly, generally leading to a higher concordance of Latin American countries, which by the end of our sample period were in almost perfect synchronicity, and to a lower concordance of the Asian countries. These results are parallel, although some differences have been noted, to those based on correlations of returns. The analysis based on return correlations, however, is probably affected too much by short-term movements of the market and, given the significant presence of outlying returns during crisis periods, they tend to give a distorted picture of the medium term evolution of the individual markets and of their concordance.

An interesting corollary is obtained from the analysis of the shape of the cycle phases. Before financial liberalization, the shape of the cycles in Latin American and Asian countries revealed significant predictabilities, by which returns showed "acceleration" patterns depending on the closeness to the turning point - peak or trough. These patterns were more marked than those in developed economies, thus making the evolution of the stock market more predictable and signalling the possible existence of inefficiencies. After liberalization, the emerging markets exhibit a behavior much more similar to that in the developed countries: Even though bear phases still 
show some acceleration effect at the end of the phase - mostly because of the financial crises of the late 1990s - the departures from what would be implied by statistical models of market evolution - and the departures from the behavior in developed economies - have been significantly reduced.

Our analysis is a first step that opens up a broad and ambitious research program. Once the stock market cycles have been identified and analyzed in their own stance, several related questions arise. First, what is the relationship between real cycles and stock market cycles? Do recessions and expansions in emerging countries have similar characteristics as bull and bear markets across countries and with respect to the developed countries? Can the differing characteristics of emerging stock markets, and the changes in those characteristics, be traced to the real side? So far, little work has been done on real cycles in emerging countries, mostly due to the lack of adequate data.

Second, our finding of increased synchronicity in emerging stock markets raises a causality question: Can the reasons be found in the real side of the economy increased convergence of fundamentals, increased symmetry in exogenous shocks that hit the economies - or is it merely a financial phenomenon - i.e. these countries just "look similar" to outside investors that can now enter the newly liberalized markets? This point raises the issue of whether emerging markets should indeed be considered an "asset class" of their own.

Third, our results suggest that future work would benefit from a deeper examination of the institutional aspects of emerging markets. Broad and potentially fruitful questions arise such as the relationship between stock market behavior and institutional depth and development - including both political and economic institutions - 
or the relationship between financial liberalization and other economic changes that emerging countries have gone through - trade liberalization or the privatization of productive sectors.

Finally, from the financial side, our results are important in the context of the literature of investment allocation and international risk diversification. The effects we have identified after liberalization of the markets - that is, after the markets become increasingly available for outside investors - seem to provide relevant information for fund allocation. We have detected a higher synchronicity of emerging market behavior - which could translate into lower benefits of diversification across emerging countries - and also that returns and volatility both decrease with liberalization. These effects are likely to affect significantly the optimal allocation of investment funds. A related question concerns the relationship of emerging stock markets with world portfolios: Is this relationship different during bull and bear phases? If it is, then again optimal rules for fund allocation may be significantly affected.

As we can see, a number of interesting questions remain unanswered. We believe that our analysis has given a first step in the direction of gaining a deeper understanding of the behavior of stock markets, although much exciting work remains to be done.

\section{Acknowledgements}

An earlier version of this paper was presented at the VII Annual Meeting of LACEA (Madrid, October 2002). We thank participants at the University of California, Santa Cruz conference on "Regional and International Implications of the Financial Instability in Latin America" for fruitful discussions. We are particularly grateful to Joshua Aizenman, Diego Valderrama, Jim Lothian and the referee for most 
helpful comments and suggestions. Financial aid from the Universidad de Navarra (Proyecto PIUNA 2001-9) is gratefully acknowledged. 


\section{References}

Aggarwal, R., Inclan, C., Leal, R.,1999. Volatility in Emerging Stock Markets. Journal of Financial and Quantitative Analysis 34, 33-55.

Aizenman, J., 2002. Financial Opening: Evidence and Policy Options. Paper presented at the Challenges to Globalization NBER-CEPR conference, May 2002.

Ammer, J., Mei, J., 1996. Measuring International Economic Linkages with Stock Market Data. Journal of Finance 51, 1743-1764.

Artis, M.J., Kontolemis, Z.G., Osborn, D.R., 1997. Business Cycles for G7 and European Countries. Journal of Business 70, 249-279.

Bekaert, G., Harvey, C.R., 2000. Capital Flows and the Behavior of Emerging Equity Markets. In Edwards, S., (Ed.), Capital Flows and the Emerging Economies: Theory, Evidence and Controversies. NBER, Cambridge, MA, pp. 159-194.

Bekaert, G., Harvey, C.R., Lumsdaine, R.L., 2002a. The Dynamics of Emerging Market Equity Flows. Journal of International Money and Finance 21, 295-350.

Bekaert, G., Harvey, C.R., Lumsdaine, R.L., 2002b. Dating the Integration of World Capital Markets. Journal of Financial Economics 65, 203-249.

Bekaert, G., Harvey, C.R., Lundblad, C., 2001. Emerging Equity Markets and Economic Development. Journal of Development Economics 66, 465-504.

Bekaert, G., Harvey, C.R., Ng, A., 2002. Market Integration and Contagion. Mimeo.

Bry, G., Boschan, C., 1971. Cyclical Analysis of Time Series: Selected Procedures and Computer Programs. NBER, New York.

Chakrabarti, R., Roll, R., 2002. East Asia and Europe during the 1997 Asian Collapse: A Clinical Study of a Financial Crisis. Journal of Financial Markets 5, 
$1-30$.

Chen, G.M., Firth, M., Rui, O.M., 2002. Stock Market Linkages: Evidence from Latin America. Journal of Banking and Finance 26, 1113-1141.

Choudhry, T., 1996. Stock Market Volatility and the Crash of 1987: Evidence from Six Emerging Markets. Journal of International Money and Finance 15, 969-981.

De Gregorio, J., Edwards, S., Valdes, R., 2000. Controls on Capital Inflows: Do they work? Journal of Development Economics 63, 59-83.

DeLong, J.B., 1992. Bull and Bear in the United States. In: Newman, P., Milgate, M., Eatwell, J., (Eds.), The New Palgrave Dictionary of Money and Finance. Mac Millan Press Limited, London, pp 253-255.

Diebold, F.X., Rudebusch, G.D., 1996. Measuring Business Cycles: A Modern Perspective. Review of Economics and Statistics 78, 67-77.

Edwards, S., 1995. Crisis and Reform in Latin America: From Despair to Hope. Oxford University Press, Oxford.

Edwards, S., 1999. How Effective are Capital Controls? Journal of Economic Perspectives 13, 65-84.

Edwards, S., 2000. Contagion. World Economy 23, 873-900.

Edwards, S., 2003. Review of Joseph E. Stiglitz's Globalization and its Discontents. Journal of Development Economics 70, 252-257.

Edwards, S., Susmel, R., 2003. Interest Rate Volatility and Contagion in Emerging Markets: Evidence from the 1990s. Review of Economics and Statistics (forthcoming).

Eichengreen, B., 2003. Capital Flows and Crises. MIT Press, Cambridge, MA.

Eichengreen, B., Mody, A., 2000. What Explains the Changing Spreads on Emerging Market Debt? In: Edwards, S. (ed.), The Economics of International Capital 
Flows. University of Chicago Press, Chicago.

Fischer, S., 2002. Financial Crises and Reform of the International Financial System. NBER Working Paper 9297.

Forbes, K., Rigobon, R., 2002. No Contagion, only Interdependence: Measuring Stock Market Comovements. Journal of Finance 57, 2223-2261.

Galbraith, J.K., 1954. The Great Crash. Riverside Press, Cambridge, UK.

Goldman Sachs, 2002. GS Watch. A New Framework for Predicting Financial Crises in Emerging Markets.

Goldstein, M., 2003. Debt Sustainability, Brazil, and the IMF. IIE Working Paper 03-1.

Gómez Biscarri, J., Pérez de Gracia, F., 2002. Stock Market Cycles and Stock Market Development in Spain. Universidad de Navarra Department of Economics Working Paper 01/02.

Goodwin, T.H., 1993. Business-Cycle Analysis with a Markov-Switching Model. Journal of Business and Economic Statistics 11, 331-339.

Hamilton, J.D., 1989. A New Approach to the Economic Analysis of Nonstationary Time Series and the Business Cycle. Econometrica 57, 357-384.

Hamilton, J.D., 2003. Comment on 'A Comparison of Two Business Cycle Dating Methods.' Journal of Economic Dynamics and Control 27, 1691-1693.

Hamilton, J.D., Lin, G., 1996. Stock Market Volatility and the Business Cycle. Journal of Applied Econometrics 11, 573-593.

Harding, D., Pagan, A.R., 2000. Knowing the Cycle. In: Backhouse, R.E., Salanti, A., (Eds.), Macroeconomics and the Real World - Volume 1: Econometric Techniques and Macroeconomics. Oxford University Press, Oxford, pp. 23-42. 
Harding, D., Pagan, A.R., 2002. Dissecting the Cycle: A Methodological Investigation. Journal of Monetary Economics 49, 365-381.

Harding, D., Pagan, A.R., 2003a. A Comparison of two Business Cycle Dating Methods. Journal of Economic Dynamics and Control 27, 1681-1690.

Harding, D., Pagan, A.R., 2003b. Rejoinder to James Hamilton. Journal of Economic Dynamics and Control 27, 1695-1698.

Janakiramanan, S., Lamba, A.S., 1998. An Empirical Examination of Linkages between Pacific-Basin Stock Markets. Journal of International Financial Markets 8, $155-173$.

Kaminsky, G., Reinhart, C., 2002. Financial Markets in Times of Stress. Journal of Development Economics 69, 451-470.

Karolyi, G.A., Stulz, R., 1996. Why Do Markets Move Together? An Investigation of US-Japanese Stock Return Comovements. Journal of Finance 51, 951-986.

Keynes, J.M., 1936. The General Theory of Employment, Interest and Money. Reprinted in The Collected Writings of John Maynard Keynes, vol.7. Macmillan Press Limited, London, 1973.

Kim, C., Nelson, C.R., 1999. State-Space Models with Regime Switching. MIT Press, Cambridge, MA.

King, M., Wadhwani, S., 1990. Transmission of Volatility between Stock Markets. Review of Financial Studies 3, 5-33.

Krugman, P., 2000. The Return of Depression Economics. Norton, New York. Lee, S.B., Kim, K.J., 1993. Does the October 1987 Crash strengthen the Comovements among National Stock Markets? Review of Financial Economics 3, 89102. 
Maddala, G.S., Li, H., 1996. Bootstrap Based Tests in Financial Modeling. In: Maddala, G.S. and Rao, C.R., (Eds.), Handbook of Statistics Vol. 14: Statistical Methods in Finance. North-Holland Publishers, Amsterdam, pp. 463-488.

Maheu, J.M., McCurdy, T.H., 2000. Identifying Bull and Bear Markets in Stock Returns. Journal of Business and Economic Statistics 18, 100-112.

Pagan, A.R., 2002. Learning about Models and their Fit to the Data. International Economic Journal 16, 1-18.

Pagan, A.R., Sossounov, K.A. 2003. A Simple Framework for Analyzing Bull and Bear Markets. Journal of Applied Econometrics 18, 23-46.

Ramchand, L., Susmel, R. 1998. Volatility and Cross Correlation across Major Stock Markets. Journal of Empirical Finance 5, 397-416.

Rigobon, R., 2003. On the Measurement of the International Propagation of Shocks: Is it Stable? Journal of International Economics (forthcoming).

Shiller, R.J., 1989. Market Volatility. MIT Press, Cambridge, MA.

Shiller, R.J., 2000. Irrational Exuberance. Broadway Books, New York.

Siegel, J.J., 1998. Stocks for the Long Run. McGraw-Hill, New York.

Stiglitz, J., 2002. Globalization and its Discontents. Norton, New York.

Watson, M.W., 1994. Business-Cycle Durations and Postwar Stabilization of the US Economy. American Economic Review 84, 24-46.

Wolf, H., 1996. Comovements among Emerging Equity Markets. In: Glick, R., (Ed.), Managing Capital Flows and Exchange Rates. Perspectives from the Pacific Basin. Cambridge University Press, Cambridge, MA., pp. 267-285. 
Table 1: Dates of the Peaks and Troughs

\begin{tabular}{|c|c|c|c|c|c|c|c|}
\hline & $A R G$ & $\overline{B R A}$ & $\mathrm{CHI}$ & $K O R$ & $M E X$ & THAI & $U S$ \\
\hline Trough & & & & & $1976: 10$ & & \\
\hline Peak & 1976:08 & & & & & & 1976:12 \\
\hline Trough & $1977: 10$ & & & & & & 1978:02 \\
\hline Peak & & & & 1978:08 & 1979:04 & 1978:10 & \\
\hline Trough & & & & & & & \\
\hline Peak & 1980:02 & & 1980:06 & & & & 1980:11 \\
\hline Trough & & 1981:03 & & 1980:12 & & & \\
\hline Peak & & 1982:05 & & 1981:06 & & & \\
\hline Trough & 1982:10 & & & 1982:05 & 1982:12 & 1982:03 & 1982:07 \\
\hline Peak & & & & 1983:04 & & 1983:08 & 1983:06 \\
\hline Trough & & 1983:08 & 1983:06 & 1983:11 & & & \\
\hline Peak & 1984:03 & & 1984:05 & & 1984:02 & & \\
\hline Trough & & & & & & & 1984:05 \\
\hline Peak & & & & 1984:12 & & & \\
\hline Trough & 1985:05 & & 1985:02 & 1985:05 & 1985:07 & 1986:05 & \\
\hline Peak & 1985:09 & 1986:04 & & & 1987:09 & & 1987:08 \\
\hline Trough & $1987: 10$ & 1987:12 & & & $1987: 12$ & & 1987:11 \\
\hline Peak & & & & & & 1988:07 & \\
\hline Trough & & & & & & 1988:12 & \\
\hline Peak & 1988:09 & 1989:04 & & 1989:03 & & & \\
\hline Trough & 1989:02 & & & & & & \\
\hline Peak & & & 1990:03 & & & 1990:07 & 1990:05 \\
\hline Trough & & 1990:12 & 1990:10 & 1990:08 & & 1990:11 & 1990:10 \\
\hline Peak & & & & 1991:07 & & & \\
\hline Trough & & & & 1992:07 & & & \\
\hline Peak & 1992:05 & 1992:04 & 1992:06 & & 1992:03 & & \\
\hline Trough & 1992:11 & 1992:11 & 1993:04 & & 1992:09 & & \\
\hline Peak & 1994:01 & 1994:09 & & 1994:10 & 1994:01 & 1993:12 & 1994:01 \\
\hline Trough & 1995:02 & 1995:03 & & & 1995:02 & 1995:01 & 1994:06 \\
\hline Peak & & & 1995:06 & & & 1996:01 & \\
\hline Trough & & & 1996:12 & & & & \\
\hline Peak & 1997:09 & 1997:07 & 1997:07 & & 1997:09 & & \\
\hline Trough & 1998:08 & 1999:01 & 1998:08 & 1998:09 & 1998:08 & 1998:08 & \\
\hline Peak & 2000:02 & 2000:03 & 2000:01 & 1999:12 & 2000:03 & 1999:06 & 2000:08 \\
\hline
\end{tabular}


Table 2: Characteristics of the Bull and Bear Markets for the Specific Countries

PANEL A: FULL SAMPLE

\begin{tabular}{|c|c|c|c|c|c|c|c|c|}
\hline & $A R G$ & $B R A$ & $C H I$ & $K O R$ & $M E X$ & THAI & $U S^{a}$ & $G E R^{a}$ \\
\hline \multicolumn{9}{|l|}{ Bull } \\
\hline$D$ & 20.2 & 20.3 & 23.7 & 18.4 & 26.7 & 21 & 31.9 & 26.8 \\
\hline$A$ & 1.42 & 1.26 & 0.88 & 0.79 & 1.42 & 0.84 & 0.52 & 0.528 \\
\hline$E X$ & 0.045 & -0.012 & 0.316 & 0.224 & 0.019 & 0.05 & 0.05 & 0.036 \\
\hline$V$ & 0.143 & 0.116 & 0.066 & 0.075 & 0.084 & 0.058 & 0.026 & 0.034 \\
\hline$B^{+}$ & 0.88 & 0.86 & 0.83 & 0.43 & 0.86 & 0.67 & 0.86 & 0.88 \\
\hline \multicolumn{9}{|l|}{ Bear } \\
\hline$D$ & 15 & 14.3 & 15.5 & 18.1 & 15.7 & 26 & 8.7 & 13.6 \\
\hline$A$ & -1.23 & -1.14 & -0.69 & -0.679 & -1.13 & -0.5 & -0.14 & -0.28 \\
\hline$E X$ & -0.14 & -0.09 & -0.089 & -0.077 & 0.076 & -0.134 & 0.006 & -0.025 \\
\hline$V$ & 0.144 & 0.146 & 0.074 & 0.081 & 0.113 & 0.04 & 0.024 & 0.042 \\
\hline$B^{-}$ & 1 & 1 & 0.83 & 0.71 & 1 & 0.67 & 0.14 & 0.4 \\
\hline
\end{tabular}

Sample period for all countries is 1975:12 to 2001:01, thus yielding a total number of observations of 302. For the US we use our own calculation using the peaks and troughs in Pagan and Sossounov (2003) and the S\&P500 index. For Germany we use the peaks and troughs in Gómez Biscarri and Pérez de Gracia (2002), for the period 1970:01 to 1999:11.

D: Average duration in months

A: Average amplitude in \% return (or loss)

EX: Excess from a triangle approximation

V: Volatility within the phase in average size of $\%$ return per month

B: Proportion of "big swings"

${ }^{a}$ Our own calculations. 
Table 2 (continued): Characteristics of the Bull and Bear Markets for the Specific Countries

PANEL B: PRE-REFORM (1975-1989 for the US and Germany)

\begin{tabular}{lcccccccc}
\hline & ARG & BRA & CHI & KOR & MEX & THAI & $U^{a}$ & $G^{a} R^{a}$ \\
\hline Bull & & & & & & & & \\
$D$ & 15 & 20.7 & 36 & 19 & 23.3 & 20.3 & 28.3 & 25.4 \\
$A$ & 1.66 & 1.44 & 1.22 & 0.76 & 1.70 & 0.85 & 0.49 & 0.47 \\
$E X$ & 0.065 & -0.026 & 0.411 & 0.313 & -0.182 & 0.02 & -0.015 & 0.045 \\
$V$ & 0.178 & 0.144 & 0.066 & 0.069 & 0.099 & 0.069 & 0.029 & 0.036 \\
$B^{+}$ & 1 & 0.67 & 0.5 & 0.5 & 1 & 0.67 & 0.75 & 0.6 \\
\hline Bear & & & & & & & & \\
$D$ & 18 & 17.5 & 22.5 & 13.6 & 21.3 & 21 & 12 & 8 \\
$A$ & -1.56 & -1.48 & -1.31 & -0.47 & -1.5 & -0.83 & -0.18 & -0.21 \\
$E X$ & -0.145 & -0.086 & -0.042 & -0.058 & 0.147 & -0.108 & 0.02 & 0.004 \\
$V$ & 0.157 & 0.137 & 0.09 & 0.074 & 0.114 & 0.068 & 0.024 & 0.036 \\
$B^{-}$ & 0.8 & 1 & 1 & 0.4 & 0.67 & 0.83 & 0.25 & 0.4 \\
\hline
\end{tabular}

PANEL C: POST-REFORM (1990-2001 for the US and Germany)

\begin{tabular}{lcccccccc}
\hline & ARG & BRA & CHI & KOR & MEX & THAI & $U S^{a}$ & GER \\
\hline Bull & & & & & & & & \\
$D$ & 25.5 & 16.5 & 17.5 & 17.7 & 29.3 & 19.7 & 36.7 & 24.7 \\
$A$ & 1.18 & 0.91 & 0.70 & 0.83 & 1.2 & 0.87 & 0.56 & 0.62 \\
$E X$ & 0.082 & 0.123 & 0.127 & 0.098 & 0.162 & -0.024 & 0.118 & 0.012 \\
$V$ & 0.122 & 0.093 & 0.065 & 0.084 & 0.074 & 0.08 & 0.023 & 0.039 \\
$B^{+}$ & 0.75 & 0.75 & 0.75 & 0.33 & 0.75 & 0.33 & 0.67 & 1 \\
\hline Bear & & & & & & & & \\
$D$ & 10 & 17 & 12 & 29.5 & 10 & 16 & 4.3 & 7 \\
$A$ & -0.69 & -1.29 & -0.38 & -1.19 & -0.76 & -1.16 & -0.08 & -0.26 \\
$E X$ & 0.088 & 0.107 & 0.002 & 0.039 & 0.135 & -0.17 & 0.005 & 0.042 \\
$V$ & 0.106 & 0.153 & 0.06 & 0.088 & 0.11 & 0.12 & 0.025 & 0.059 \\
$B^{-}$ & 1 & 1 & 0.75 & 1 & 1 & 1 & 0 & 0.25
\end{tabular}

Sample period for all countries is 1975:12 to 2001:01, thus yielding a total number of observations of 302. For the US we use our own calculation using the peaks and troughs in Pagan and Sossounov (2003) and the S\&P500 index. For Germany we use the peaks and troughs in Gómez Biscarri and Pérez de Gracia (2002), for the period 1970:01 to 1999:11.

D: Average duration in months

A: Average amplitude in \% return (or loss)

EX: Excess from a triangle approximation

V: Volatility within the phase in average size of $\%$ return per month

B: Proportion of "big swings"

${ }^{a}$ Our own calculations. 
Table 3: Concordance Index

PANEL A: FULL SAMPLE

\begin{tabular}{rrrrrrrr}
\hline CI & ARG & BRA & CHI & KOR & MEX & THAI & $U S$ \\
\hline ARGENTINA & 1 & 0.579 & 0.642 & 0.460 & $0.762^{a}$ & 0.636 & 0.639 \\
BRAZIL & & 1 & 0.5 & 0.536 & 0.586 & 0.387 & 0.483 \\
CHILE & & & 1 & 0.652 & $0.689^{a}$ & 0.629 & 0.632 \\
KOREA & & & & 1 & 0.586 & $0.659^{a}$ & 0.483 \\
MEXICO & & & & & 1 & $0.702^{a}$ & 0.632 \\
THAILAND & & & & & & 1 & 0.573 \\
\hline
\end{tabular}

PANEL B: PRE-REFORM (1975-1989)

\begin{tabular}{rrrrrrrr}
\hline$C I$ & $A R G$ & BRA & $C H I$ & KOR & MEX & THAI & \multicolumn{1}{c}{$U S$} \\
\hline ARGENTINA & 1 & 0.426 & 0.639 & 0.420 & 0.604 & 0.586 & 0.586 \\
BRAZIL & & 1 & 0.361 & 0.485 & 0.444 & $0.249^{b}$ & 0.379 \\
CHILE & & & 1 & 0.627 & $0.751^{a}$ & 0.627 & $0.686^{a}$ \\
KOREA & & & & 1 & 0.627 & $0.692^{a}$ & 0.562 \\
MEXICO & & & & & 1 & $0.710^{a}$ & 0.568 \\
THAILAND & & & & & & 1 & 0.550 \\
\hline
\end{tabular}

PANEL C: POST-REFORM (1990-2001)

\begin{tabular}{rrrrrrrr}
\hline$C I$ & ARG & BRA & \multicolumn{1}{c}{ CHI } & KOR & MEX & THAI & \multicolumn{1}{c}{$U S$} \\
\hline ARGENTINA & 1 & $0.774^{a}$ & 0.647 & 0.511 & $0.962^{a}$ & $0.699^{a}$ & $0.707^{a}$ \\
BRAZIL & & 1 & $0.677^{a}$ & 0.602 & $0.767^{a}$ & 0.564 & 0.617 \\
CHILE & & & 1 & $0.684^{a}$ & 0.609 & 0.632 & 0.564 \\
KOREA & & & & 1 & 0.534 & 0.617 & 0.383 \\
MEXICO & & & & & 1 & $0.692^{a}$ & $0.714^{a}$ \\
THAILAND & & & & & & 1 & 0.602 \\
\hline
\end{tabular}

The ${ }^{a}$ indicates significance at the $5 \%$ confidence level with positive correlation. ${ }^{b}$ indicates significant negative correlation. The confidence intervals have been calculated from simulated series using a random walk with drift and $\operatorname{AR}(1)$ increments,

$$
\Delta p_{t}=\mu+\rho \Delta p_{t-1}+\sigma \varepsilon_{t}, \quad \varepsilon_{t} \rightarrow \operatorname{nid}(0,1)
$$

that represents the best fitting model to the stock market cycle characteristics. Parameters of this model were estimated for all six countries, and then 10,000 series of length 302 were simulated and the $C I$ calculated. The $2.5 \%$ and $97.5 \%$ quantiles of the simulated distribution of the $C I$ are used as critical values. The specific values are available upon request. The $C I$ with respect to the US has been calculated with the series of bullish/bearish markets for the US in Table 1. 
Table 4: Simple Correlations of Returns

PANEL A: FULL SAMPLE

\begin{tabular}{rrrrrrr}
\hline$\rho$ & $A R G$ & $B R A$ & $C H I$ & \multicolumn{1}{c}{ KOR } & MEX & THAI \\
\hline$A R G E N T I N A$ & 1 & 0.03 & 0.17 & -0.0256 & $0.192^{a}$ & 0.084 \\
BRAZIL & & 1 & 0.112 & 0.076 & 0.104 & 0.091 \\
CHILE & & & 1 & 0.129 & $0.225^{a}$ & 0.223 \\
KOREA & & & & 1 & 0.137 & $0.376^{a}$ \\
MEXICO & & & & & 1 & $0.262^{a}$ \\
THAILAND & & & & & & 1 \\
\hline
\end{tabular}

PANEL B: PRE-REFORM (1975-1989)

\begin{tabular}{rrrrrrr}
\hline$\rho$ & $A R G$ & $B R A$ & $C H I$ & $K O R$ & $M E X$ & $T H A I$ \\
\hline$A R G E N T I N A$ & 1 & -0.07 & 0.114 & -0.11 & 0.106 & -0.011 \\
BRAZIL & & 1 & -0.04 & 0.074 & 0.067 & $-0.071^{b}$ \\
CHILE & & & 1 & 0.041 & $0.153^{a}$ & 0.121 \\
KOREA & & & & 1 & 0.071 & $-0.011^{a}$ \\
MEXICO & & & & & 1 & $0.255^{a}$ \\
THAILAND & & & & & & 1 \\
\hline
\end{tabular}

PANEL C: POST-REFORM (1990-2001)

\begin{tabular}{rrrrrrr}
\hline$\rho$ & $A R G$ & BRA & \multicolumn{1}{c}{ CHI } & KOR & MEX & THAI \\
\hline ARGENTINA & 1 & $0.306^{a}$ & 0.433 & 0.124 & $0.555^{a}$ & $0.283^{a}$ \\
BRAZIL & & 1 & $0.392^{a}$ & 0.086 & $0.407^{a}$ & 0.201 \\
CHILE & & & 1 & $0.257^{a}$ & 0.422 & 0.381 \\
KOREA & & & & 1 & 0.242 & 0.542 \\
MEXICO & & & & & 1 & $0.341^{a}$ \\
THAILAND & & & & & & 1 \\
\hline
\end{tabular}

The ${ }^{a}$ indicate that the $C I$ in Table 4 is outside of the $5 \%$ confidence interval and shows positive correlation. ${ }^{b}$ indicates significant negative correlation. 
Table 5

Simulated Critical Values of the EX index

\begin{tabular}{|c|c|c|c|c|c|c|c|c|c|c|c|c|c|c|}
\hline & \multicolumn{2}{|c|}{ ARG } & \multicolumn{2}{|c|}{ BRA } & \multicolumn{2}{|c|}{ CHI } & \multicolumn{2}{|c|}{ KOR } & \multicolumn{2}{|c|}{ MEX } & \multicolumn{2}{|c|}{ THAI } \\
\hline & & & Bull & Bear & Bull & Bear & Bull & Bear & Bull & Bear & Bull & Bear & Bull & Bear \\
\hline \multirow{3}{*}{ FULL } & Model I & $\overline{\mathrm{CU}}$ & 0.195 & -0.216 & 0.1036 & -0.196 & 0.153 & -0.081 & 0.0854 & -0.124 & 0.1382 & -0.178 & 0.0816 & -0.141 \\
\hline & & Upp & 0.388 & -0.085 & 0.2148 & -0.09 & 0.2939 & -0.018 & 0.1769 & -0.052 & 0.2839 & -0.077 & 0.1638 & -0.061 \\
\hline & 1780uce & Lower CV & 0.1432 & -0.335 & 0.0931 & -0.284 & 0.1118 & -0.07 & 0.1253 & -0.09 & 0.1169 & -0.15 & 0.0682 & -0.362 \\
\hline \multirow[t]{4}{*}{ SAMPLE } & & Upper CV & 3785 & -0.108 & 0.2647 & -0.109 & 0.2206 & -0.018 & 0.2611 & -0.015 & 0.2488 & -0.055 & 0.33 & -0.07 \\
\hline & Model II] & Lower CV & 1013 & -0.282 & 0.1006 & -0.296 & .1141 & -0.067 & 0.1439 & -0.096 & 0.1533 & -0.136 & .0628 & -0.203 \\
\hline & & & 3397 & -0.141 & 0.2502 & -0.125 & 0.2211 & -0.011 & 0.2549 & -0.009 & 0.2988 & -0.043 & 0.1856 & -0.086 \\
\hline & Model I & & 2381 & -0.264 & 0.0888 & -0.232 & 0.1839 & -0.087 & 0.1308 & -0.054 & 0.153 & -0.219 & 0.1106 & -0.045 \\
\hline \multirow{6}{*}{$\begin{array}{c}1975 \\
- \\
1989\end{array}$} & & & 1938 & -0.103 & 0.1922 & -0.113 & 0.3578 & -0.007 & 0.2532 & 0.005 & 0.3279 & -0.1 & 0.2141 & 0.0057 \\
\hline & Model II & Lower CV & 0.1328 & -0.407 & & & 0.1242 & -0.08 & 0.2073 & -0.043 & 0.1072 & -0.24 & 0.06 & -0.085 \\
\hline & & Upper CV & 3275 & -0.179 & & & 0.2457 & -0.02 & 0.405 & 0.0852 & 0.2522 & -0.095 & 0.1468 & -0.027 \\
\hline & Model III & Lower CV & 0.1273 & -0.333 & & & 0.1667 & -0.089 & 0.2104 & -0.04 & 0.1486 & -0.168 & 0.0384 & -0.078 \\
\hline & & & 0.3857 & -0.178 & & & 0.334 & -0.01 & 0.3992 & 0.0747 & 0.3212 & -0.065 & 0.1155 & -0.043 \\
\hline & Noderi & Lor & 0.1299 & -0.132 & 0.1337 & -0.154 & 0.1078 & -0.074 & 0.0594 & -0.234 & 0.1305 & -0.156 & 0.0623 & -0.266 \\
\hline \multirow{5}{*}{$\begin{array}{c}1990 \\
- \\
2001\end{array}$} & & Upp & 0.2658 & -0.051 & 0.258 & -0.065 & 0.2138 & -0.021 & 0.139 & -0.112 & 0.2605 & -0.063 & 0.1423 & -0.131 \\
\hline & Model II & Lower CV & 0.1742 & -0.089 & 0.1373 & -0.106 & 0.1015 & -0.084 & 0.0705 & -0.167 & 0.1356 & -0.105 & 0.079 & -0.221 \\
\hline & & Upper CV & 0.343 & -0.015 & 0.269 & -0.034 & 0.2064 & -0.026 & 0.1723 & -0.068 & 0.2688 & -0.033 & 0.1925 & -0.097 \\
\hline & A & Lower CV & .0856 & -0.099 & 0.1163 & -0.176 & 0.0752 & -0.095 & 0.1214 & -0.223 & 0.1137 & -0.172 & 0.0866 & -0.303 \\
\hline & & Upper CV & 1664 & -0.039 & 0.2436 & -0.078 & 0.1586 & -0.041 & 0.2218 & -0.026 & 0.248 & -0.075 & 0.1663 & -0.114 \\
\hline
\end{tabular}

The missing CV's for Brazil represent that the estimated parameters did not yield a stationary process for the variance, which

therefore prevented the EX index from being simulated 


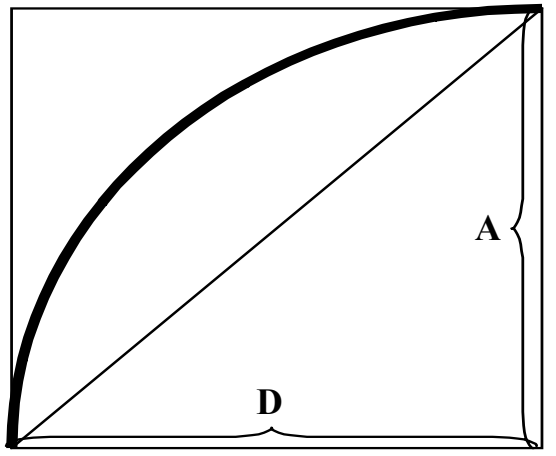

A) A Bull Market with EX $>0$

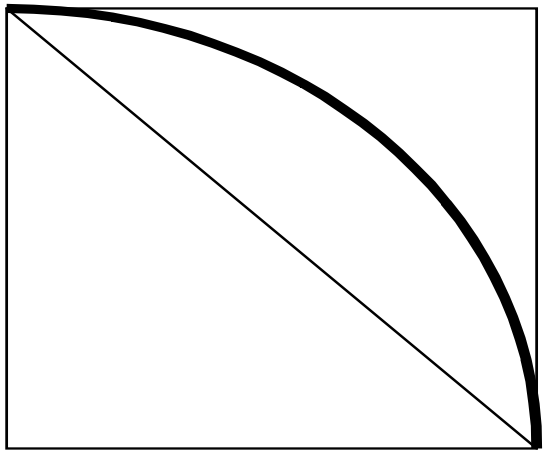

C) A Bear Market with EX $>0$

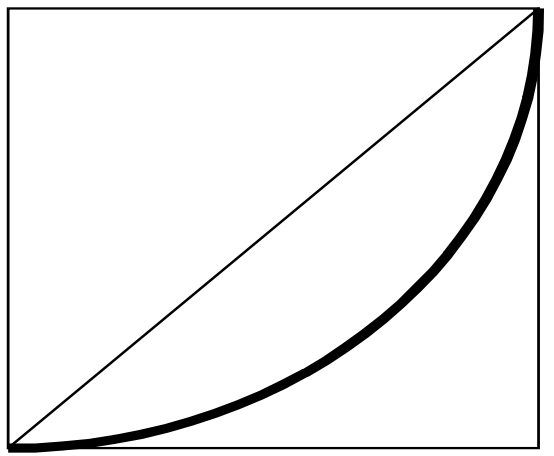

B) A Bull Market with $\mathrm{EX}<0$

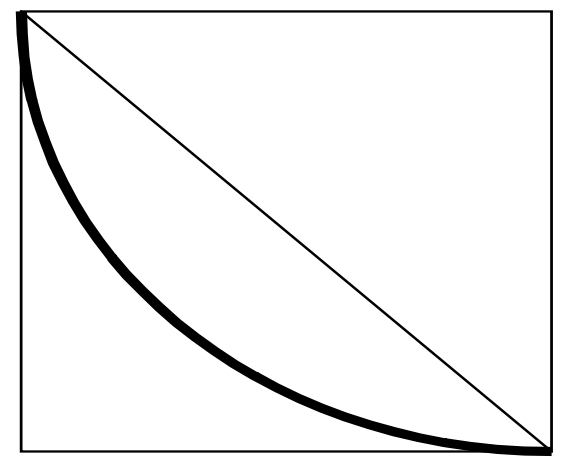

D) A Bear Market with EX $<0$

Figure 1: Shape of the Bull / Bear Phases and value of the Excess measure. Of course, the axes correspond to time and stock prices. Consequently, D corresponds to our measure of duration of the phase and A to the amplitude. 

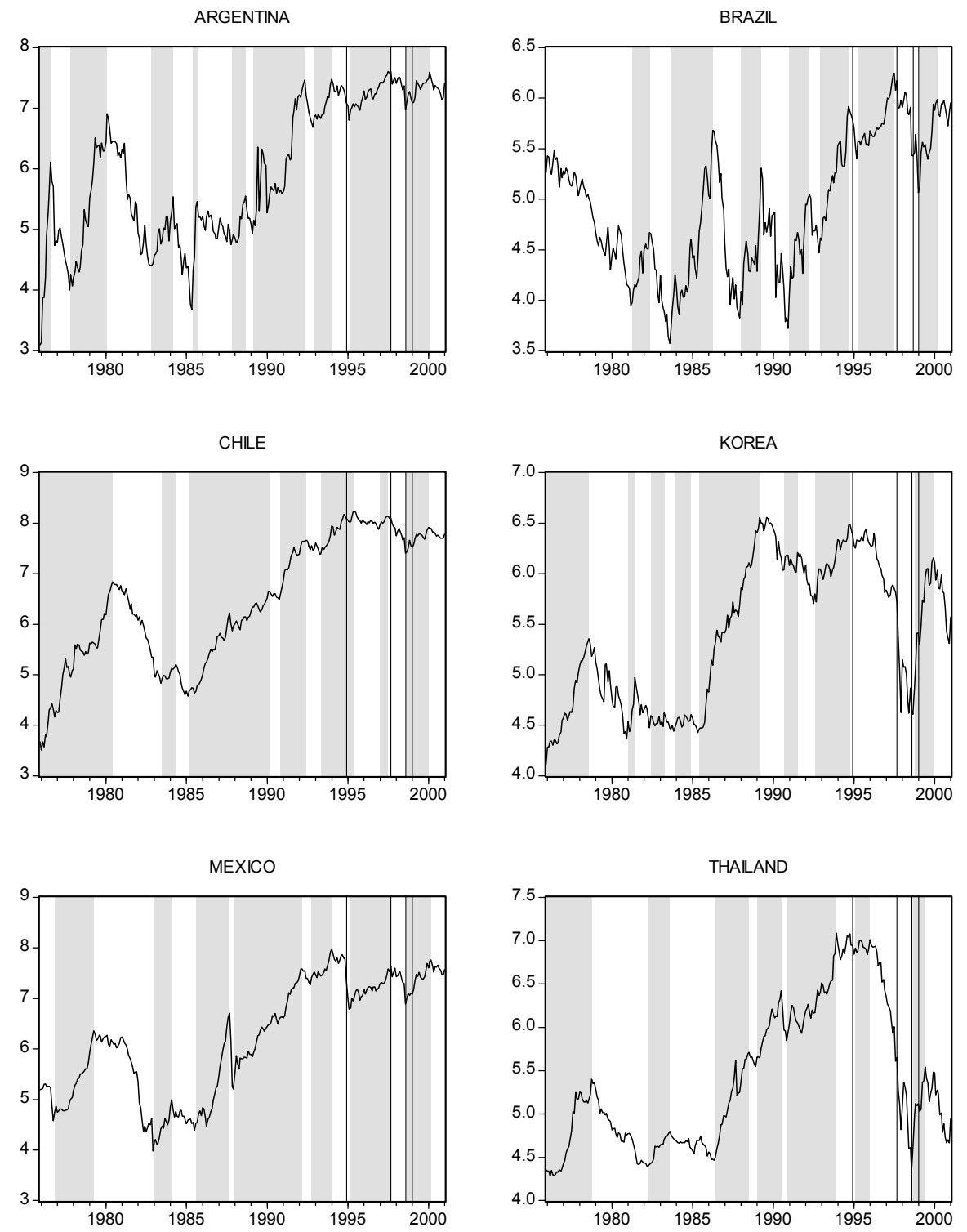

Figure 2: Country Stock Indexes. Evolution of (Log) Prices, 1975-2001. Bullish Phases shaded. The four lines correspond to the Mexican, Asian, Russian and Brazilian crises 

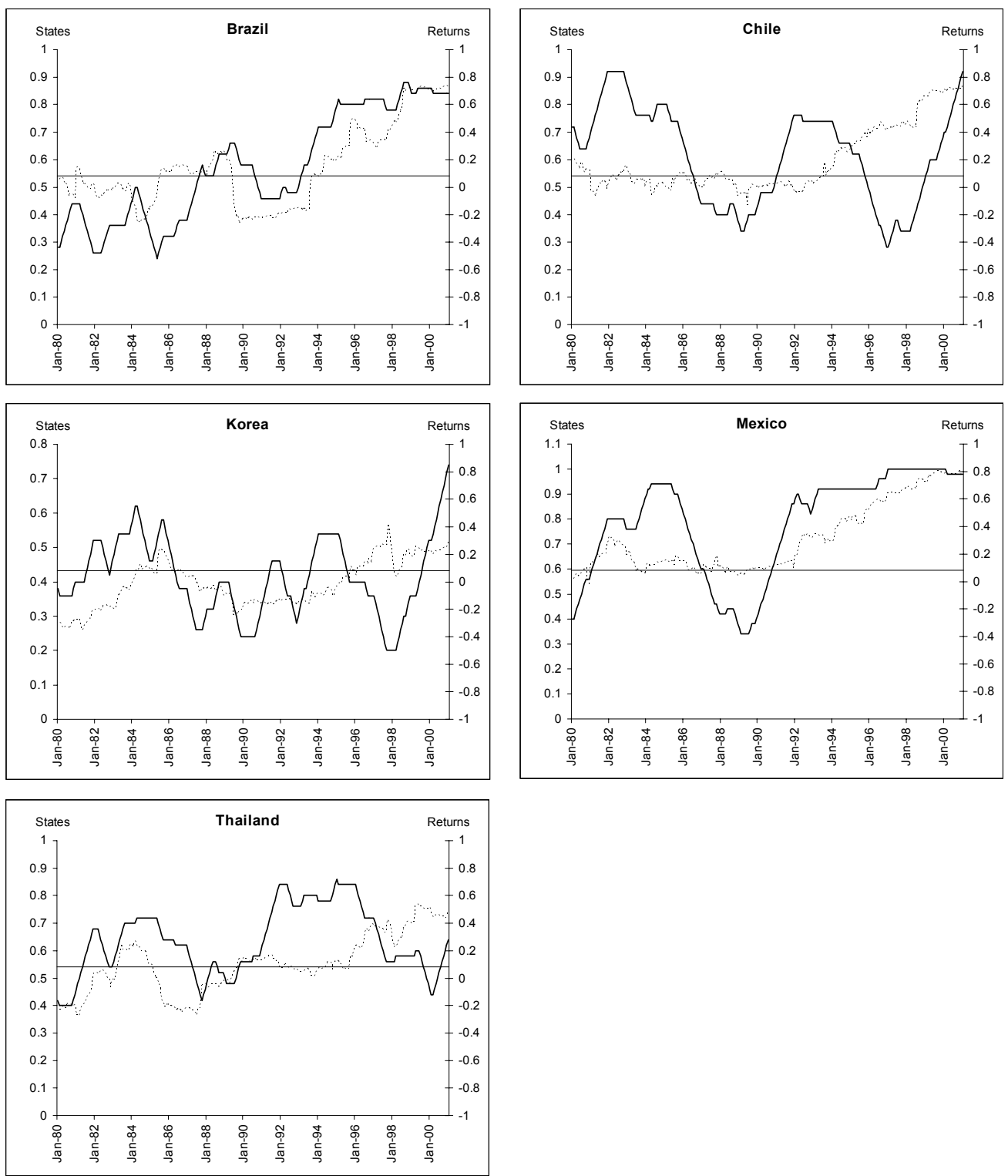

Figure 3: Argentina. Comparison of rolling correlation indexes of simple returns (dashed line) and rolling concordance indexes of bull/bear states (solid line). The rolling window has size 50 . 

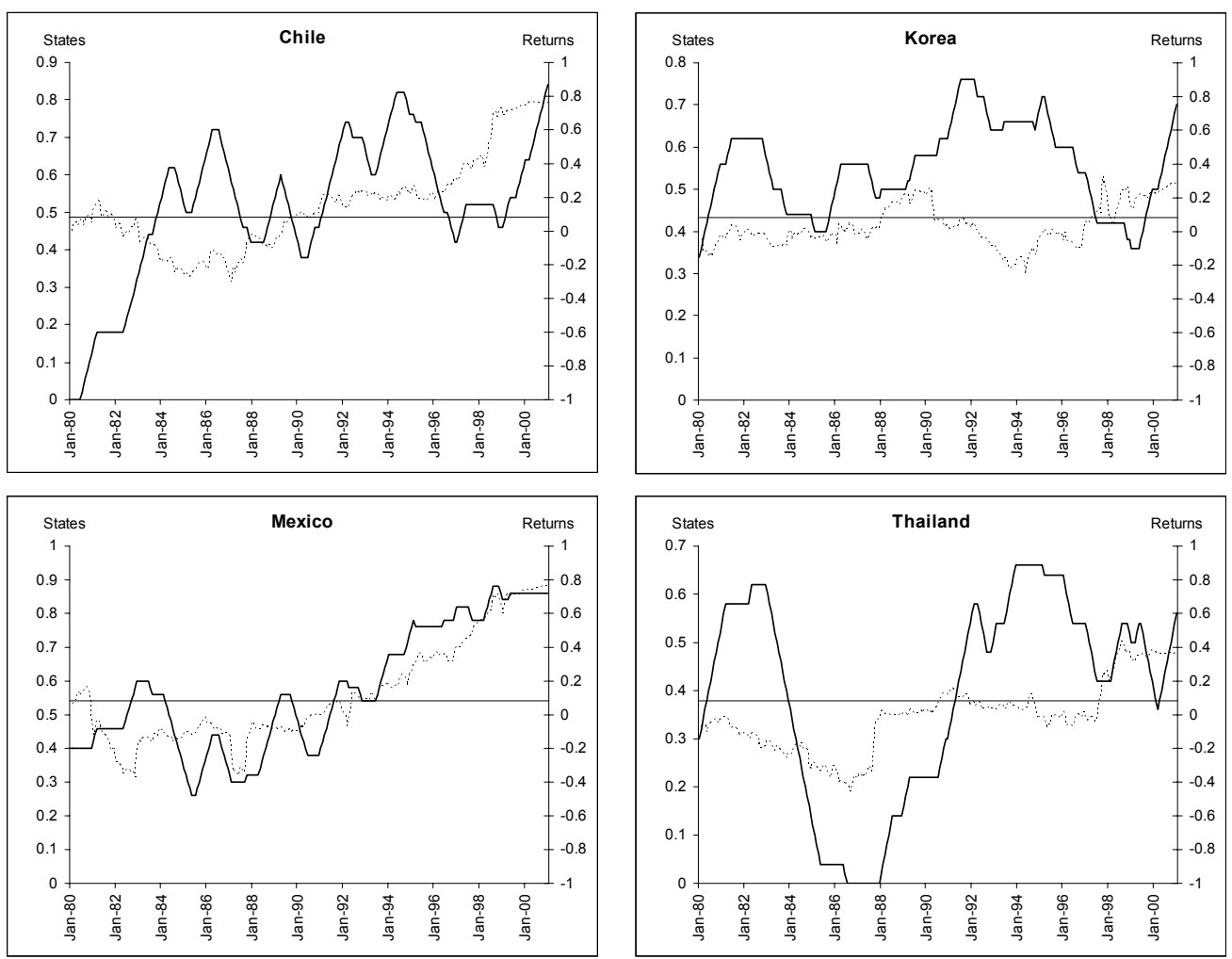

Figure 4: Brazil. Comparison of rolling correlation indexes of simple returns (dashed line) and rolling concordance indexes of bull/bear states (solid line). The rolling window has size 50 . 

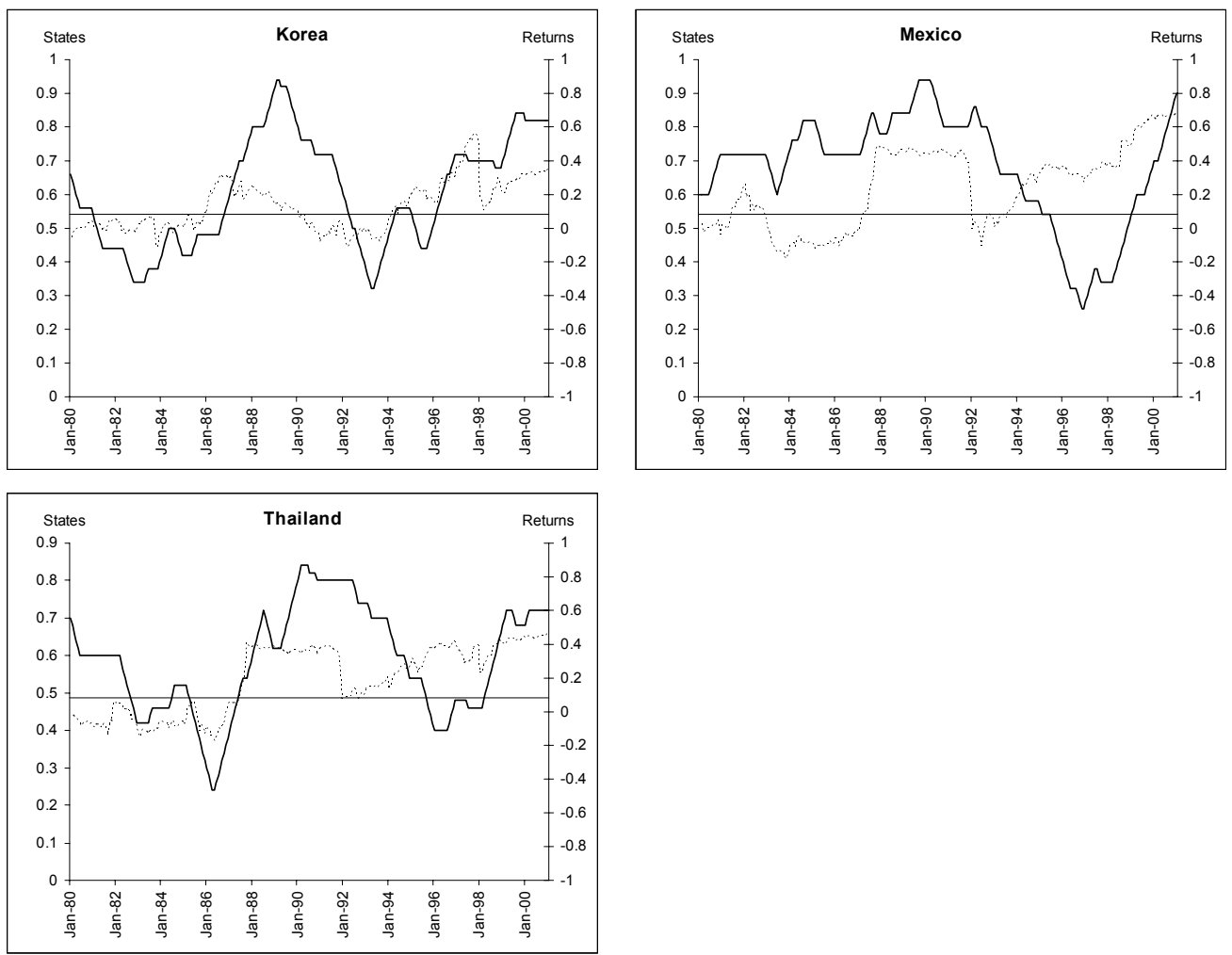

Figure 5: Chile. Comparison of rolling correlation indexes of simple returns (dashed line) and rolling concordance indexes of bull/bear states (solid line). The rolling window has size 50 . 

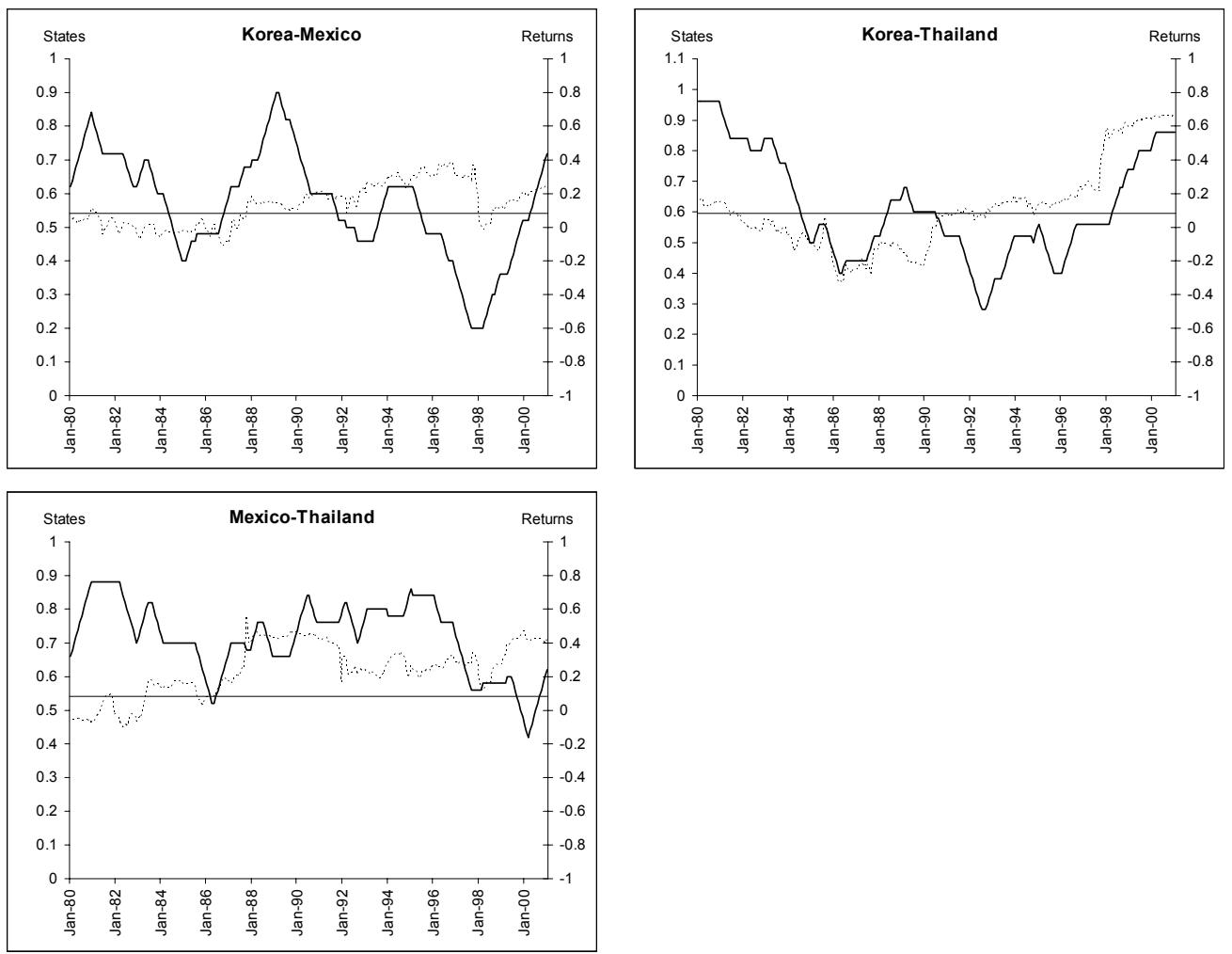

Figure 6: Mexico, Korea and Thailand. Comparison of rolling correlation indexes of simple returns (dashed line) and rolling concordance indexes of bull/bear states (solid line). The rolling window has size 50 . 